\title{
In Situ Electrochemical Cells to Study the Oxygen Evolution Reaction by Near Ambient Pressure X-ray Photoelectron Spectroscopy
}

\author{
Verena Streibel ${ }^{1} \cdot$ Michael Hävecker $^{1,2} \cdot$ Youngmi Yi $^{1,2} \cdot$ Juan J. Velasco Vélez ${ }^{1,2} \cdot$ Katarzyna Skorupska $^{1,2}$. \\ Eugen Stotz ${ }^{1} \cdot$ Axel Knop-Gericke $^{1} \cdot$ Robert Schlögl $^{1,2} \cdot$ Rosa Arrigo $^{3}$
}

Published online: 17 October 2018

(c) The Author(s) 2018

\begin{abstract}
In this contribution, we report the development of in situ electrochemical cells based on proton exchange membranes suitable for studying interfacial structural dynamics of energy materials under operation by near ambient pressure X-ray photoelectron spectroscopy. We will present both the first design of a batch-type two-electrode cell prototype and the improvements attained with a continuous flow three-electrode cell. Examples of both sputtered metal films and carbon-supported metal nanostructures are included demonstrating the high flexibility of the cells to study energy materials. Our immediate focus was on the study of the oxygen evolution reaction, however, the methods described herein can be broadly applied to reactions relevant in energy conversion and storage devices.
\end{abstract}

Keywords Near ambient pressure X-ray photoelectron spectroscopy (NAP-XPS) - Electrochemistry · Oxygen evolution reaction $(\mathrm{OER}) \cdot$ Low temperature polymeric electrolyte electrode assembly $\cdot$ Platinum $\cdot$ Iridium

\section{Introduction}

Renewable energy storage and conversion technologies rely on the availability of materials able to catalyse, electrochemically or photo-electrochemically activated, hydrogenation and dehydrogenation reactions of small molecules at potentials as close as possible to the corresponding thermodynamic potential $[1,2]$. Most of the commonly investigated redox systems are inspired by the energy cycles occurring in nature: (1) the oxygen redox cycle $\left(\mathrm{O}_{2} / \mathrm{H}_{2} \mathrm{O}\right)$, (2) the nitrogen redox cycle $\left(\mathrm{N}_{2} / \mathrm{NH}_{3}\right)$, and (3) the carbon redox cycle $\left(\mathrm{CO}_{2} /\right.$ $\mathrm{C}_{\mathrm{x}} \mathrm{H}_{\mathrm{y}} \mathrm{O}_{\mathrm{z}}$ ). Whilst literature on these topics is flourishing

Verena Streibel

vpfeifer@fhi-berlin.mpg.de

$\triangle$ Rosa Arrigo

rosa.arrigo@diamond.ac.uk

1 Department of Inorganic Chemistry, Fritz-Haber-Institut der Max-Planck-Gesellschaft, Faradayweg 4-6, 14195 Berlin, Germany

2 Department of Heterogeneous Reactions, Max-Planck-Institut für Chemische Energiekonversion, Stiftstr. 34-36, 45470 Mülheim, Germany

3 Diamond Light Source Ltd, Harwell Science and Innovation Campus, Didcot, Oxfordshire, OX 11 0DE, UK
[1-3], no satisfactory materials have been found to provide the decisive boost for these technologies. The major challenges to face are common to the three systems: (1) reducing material costs, (2) improving the energy efficiencies to practical levels, and (3) reducing material degradation during operation. A thorough understanding of the underlying mechanisms is generally acknowledged to guide towards the synthesis of improved materials. In this respect, for electrochemical processes the understanding of the restructuring and compositional change of the electrode surface upon polarization, activation, and deactivation is especially important. This knowledge can be attained via surface-sensitive in situ spectroscopic techniques that investigate the electronic structure at surfaces and interfaces.

Synchrotron-based soft X-ray photoelectron and absorption spectroscopies are striking methodologies to serve this purpose. Traditionally a vacuum technique, X-ray photoelectron spectroscopy (XPS) nowadays is an established tool for investigating the gas-solid interface. In its "high pressure" configuration, the technique is generally referred to as (near) ambient pressure XPS (NAP-XPS), where near ambient means a working pressure of up to a few millibars [4]. Compared to ex situ, UHV-based XPS [5], NAP-XPS can help to establish more robust structure-function correlations by simultaneously monitoring changes in (1) the 
electronic structure of the working catalyst, (2) the nature of the adsorbed reactant molecules, and (3) the nature of the products formed at pressures close to relevant conditions. The application of this technique to increasingly important energy-related electrochemical processes is currently pursued at synchrotrons worldwide, with pioneering work at ALS (Berkeley) [6-9], BESSY II/HZB (Berlin) [10-15], and SSRL (Stanford) [16-18].

Studying electrochemical processes by NAP-XPS requires the development of adapted in situ electrochemical cells. In the last decade the progress in this field has been gigantic and we will now briefly provide a non-exhaustive list of proposed approaches. Depending on the type of synchrotron radiation employed, different methodologies have been put forward: The research using soft X-rays initially was focused on cells using solid oxide electrolytes $[6,19,20]$ as well as on room $[10,16,17]$ and higher [11] temperature proton exchange membrane (PEM)-based electrode assemblies in (wet) gaseous atmospheres. To investigate electrochemical reactions in liquid electrolytes by soft X-ray spectroscopies, an alternative approach uses electron-transparent graphene membranes to separate the liquid reaction environment from the vacuum section of the analysis chamber [13, 21]. In the tender X-ray regime, the excited photoelectrons have higher inelastic mean free paths (IMFP) and can penetrate thin matter: In the "dip \& pull" technique, photoelectrons are analyzed after penetrating a thin film of liquid electrolyte formed on a metal electrode [7-9]. Since photoelectrons excited by tender X-rays can penetrate ultra-thin Si membranes, in yet another approach these membranes are used to separate the liquid solution from the evacuated analyzer chamber [22]. Recently, also hard X-ray-based NAP-XPS generating photoelectrons with even higher IMFPs has been successfully employed for PEM-systems [23]. Finally, liquid jet approaches can be used to study polarized interfaces [24].

Herein, we will focus on PEM-based systems to study water electrolysis with a focus on the oxygen evolution reaction (OER). Due to their practical handling and high potential for implementation in the current electricity infrastructure [25], PEM-based systems have attracted major interest from industry. From the point of view of studying PEMbased electrolyzers or fuel cells by soft X-ray-based NAPXPS, they present the complication that a high degree of hydration of the PEM is required to enable the device, which is hardly achievable with standard NAP-XPS. To overcome this limitation, we have developed dedicated in situ electrochemical cells to study water electrolysis at the ISISS (Innovative Station for In Situ Spectroscopy) beam line (HZB/ BESSY II) in Berlin. We aim to provide here a detailed assay on the experiments performed and the spectroscopic results obtained throughout the entire process of engineering optimization of these in situ electrochemical cells. We will further discuss how these experiments have helped us to probe the working oxidation states of both anions and cations in Pt- and Ir-based electrodes during the OER.

\section{Experimental}

\subsection{Proton Exchange Membrane Activation}

PEMs are commonly used as semi-permeable electrolytes in fuel cells or electrolyzers [25]. These acidic membranes conduct protons and, while they let water diffuse, they hinder the passage of gases like $\mathrm{O}_{2}$ and $\mathrm{H}_{2}$. In the present contribution, such PEMs were used as membranes between liquids and an evacuated XPS and NEXAFS (near-edge X-ray absorption fine structure) measurement chamber and simultaneously served as electrolytes for a water electrolyzer system. To investigate reactions in basic environments, the use of anion exchange membranes could be considered. In all experiments presented herein, Nafion ${ }^{\circledR} 117$ ionomers from AlfaAesar (Thermo Fischer Scientific, Karlsruhe, Germany) were employed as PEMs. Nafion ${ }^{\circledR} 117$ consists of a polytetrafluoroethylene (PTFE) backbone and regularly spaced perfluorovinyl ether pendant side chains, which are terminated by sulfonate ionic end groups $\left(\mathrm{C}_{7} \mathrm{HF}_{13} \mathrm{O}_{5} \mathrm{~S} \cdot \mathrm{C}_{2} \mathrm{~F}_{4}\right.$, see Fig. 1a) [26, 27]. Only when well hydrated, Nafion ${ }^{\circledR} 117$ is interspersed with channels that enable proton transport as schematically shown in Fig. $1 b[26,28]$.

To enable the proton conductivity of Nafion ${ }^{\circledR} 117$, the commercially obtained membranes need to be activated in a two-step process. In the pretreatment step, the membranes were purified from organic contaminants for $2 \mathrm{~h}$ at $80^{\circ} \mathrm{C}$ in a stirred solution of $3 \mathrm{vol} \% \mathrm{H}_{2} \mathrm{O}_{2}$, which was prepared from $30 \% \mathrm{H}_{2} \mathrm{O}_{2}$ ROTIPURAN® (Carl Roth, Germany) and ultra-pure Milli-Q water (18.2 M 2 ). In the activation step,

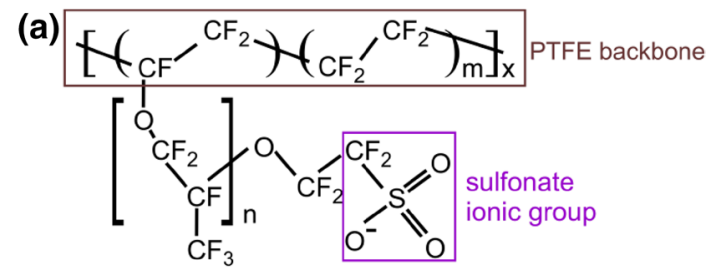

(b)

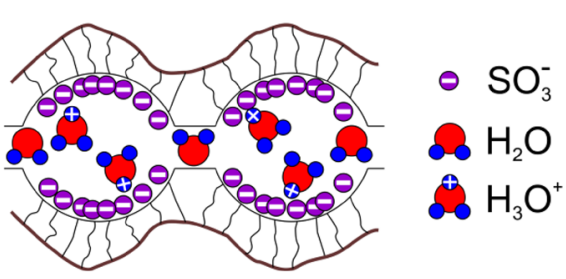

Fig. 1 a Chemical formula of Nafion ${ }^{\circledR}$ ionomer with PTFE backbone (brown) and sulfonate acid-terminated side chains (purple). b Schematic representation of Nafion $\AA$ with proton-conducting channels, adapted from [28] 
the membranes were stirred for $2 \mathrm{~h}$ at $80{ }^{\circ} \mathrm{C}$ in $0.5 \mathrm{M} \mathrm{H}_{2} \mathrm{SO}_{4}$, which was prepared from $\mathrm{H}_{2} \mathrm{SO}_{4}$ EMSURE®, 95-97\% (Merck KGaA, Darmstadt, Germany) and ultra-pure Milli$\mathrm{Q}$ water. After each step, the membranes were rinsed with ultra-pure Milli-Q water. This activation procedure yields proton-terminated sulfonate ionic end groups, which enable the proton conductivity of Nafion ${ }^{\circledR} 117$ when hydrated. After the activation, the membranes were dried and stored between clean filter paper.

\subsection{Sample Deposition}

The investigated materials were either sputter-deposited directly onto activated and dried Nafion ${ }^{\circledR} 117$ membranes or electrodeposited on carbon paper (Toray ${ }^{\mathrm{TM}}$ Carbon paper TGP-H-030, FuelCellStore.com). Other techniques that could be used to deposit electroactive materials onto the PEMs include drop-casting, spin-coating, wet transfer etc. For the sputter-deposition, we used metallic targets (Ir 99.99\%, Pt 99.99\% and bimetallic Pt 80\%/Pd 20\%, Elektronen-Optik-Service GmbH, Dortmund, Germany) in a Cressington 208HR sputter coater. The metallic films were deposited in $0.1 \mathrm{mbar}$ Ar atmosphere at a DC current of $40 \mathrm{~mA}$. Depending on the material and the desired film thickness, deposition times ranged from 60 to 300 s. For the electrodeposition, we used a three-electrode setup controlled by a VSP potentiostat (Bio-Logic Science Instruments SAS, France) with a platinized Pt wire counter electrode (CE) and a saturated calomel (SCE) reference electrode (RE). The carbon paper working electrode (WE) was polarized at the respective deposition potential until the desired mass loading was achieved. Details of the deposition steps are given in the respective manuscript sections.

\subsection{Scanning/Transmission Electron Microscopy}

The morphology of the deposited films was investigated in a scanning electron microscope (SEM) Hitachi S-4800 FEG equipped with a Bruker XFlash detector. Images were taken in both secondary electron (SE) and backscattered electron (BSE) modes with acceleration voltages of $1.5 \mathrm{kV}$ and $15 \mathrm{kV}$. The nanostructure of the films was assessed using a transmission electron microscope (TEM) FEI TITAN 80-300 with an acceleration voltage of $200 \mathrm{kV}$.

\subsection{In Situ Photoemission and Absorption Measurements}

The NAP-XPS end station at the ISISS beam line of the synchrotron radiation facility BESSY II/HZB (Berlin, Germany) served for all in situ photoelectron and absorption measurements presented herein. The system has been described in detail elsewhere [29]. In a recent upgrade, the end station has been modularized. While the lens system with the differential pumping stages and the spectrometer remain fixed, different types of reaction chamber module can be attached to the system. These exchangeable modules are specialized for categories of investigations (e.g. electrochemistry or heterogeneous oxidation catalysis) and prevent cross-contamination between different types of experiment. The dedicated electrochemistry module (EC-module) is shown in Fig. 2. The EC-module was constructed such that wet electrochemical reactions can be studied in situ by XPS and NEXAFS. The EC-module is compatible with different types of electrochemical reaction cell, two of which, namely a two- and a three-electrode cell, will be described in detail below. These cells were used to study the electronic structure of oxygen-evolving electrodes. Furthermore, the EC-module is equipped with a mass flow controller (MFC)-regulated gas inlet system through which additional reactive gases can be dosed into the measurement compartment. For gas analytics, the EC-module features a quadrupole mass spectrometer (QMS, Prisma, Pfeiffer, Vacuum, Inc., Germany). Using mass spectrometry, gases evolved at the working electrode can be detected online.

Polarization of the cell electrodes was achieved via an external connection of the cells to a modular research grade potentiostat (SP-300, Bio-Logic Science Instruments SAS, France). For the two-electrode cell, the potentiostat was operated in floating mode and the counter electrode of the cell was grounded via the contact of the stainless steel cell body and the spectrometer. The connection between the $\mathrm{CE}$ and the spectrometer aligns the Fermi levels of the materials. Hence, when the WE is polarized with respect to the CE, the actual applied potential can be read off by the observed binding energy shift of the XPS core levels. For the three-electrode setup, the potentiostat was used in grounded mode. The reference electrode of the three-electrode cell was a $\mathrm{Ag} / \mathrm{AgCl}$ micro RE (DRIREF-2SH, World Precision Instruments, USA). The continuous supply of liquid into the three-electrode cell was achieved through PEEK tubing (1/8 inch outer diameter, 1/16 inch inner diameter, SigmaAldrich) that connected the cell to an outside Teledyne ISCO 260D syringe pump. The syringe pump was used to supply the electrolyte at a constant flow rate of $1 \mathrm{ml} / \mathrm{min}$. All electrolytes filled into the cells were based on ultra-pure Milli-Q water. For the preparation of $0.1 \mathrm{M} \mathrm{H}_{2} \mathrm{SO}_{4}$, we used $\mathrm{H}_{2} \mathrm{SO}_{4}$ EMSURE®, 95-97\%, Merck KGaA, Darmstadt, Germany.

All in situ XPS and NEXAFS measurements were collected at room temperature. The focus size of the beam line, i.e. the illuminated area of the electrode, was $150 \mu \mathrm{m} \times 80 \mu \mathrm{m}$ (horizontal $\times$ vertical). While XPS measurements probe occupied electronic states, NEXAFS measurements probe unoccupied electronic states.

For all XPS measurements, we used an exit slit setting of the beam line of $111 \mu \mathrm{m}$. In this work, depending on 
Fig. 2 a Construction model and $\mathbf{b}$ photograph of the electrochemistry module (EC-module) compatible with the NAP-XPS end station at the ISISS beamline at BESSY II/HZB. The photograph in $\mathbf{b}$ shows in addition to the EC-module the rack with the syringe pump for the continuous electrolyte supply and the external potentiostat to polarize the working electrode

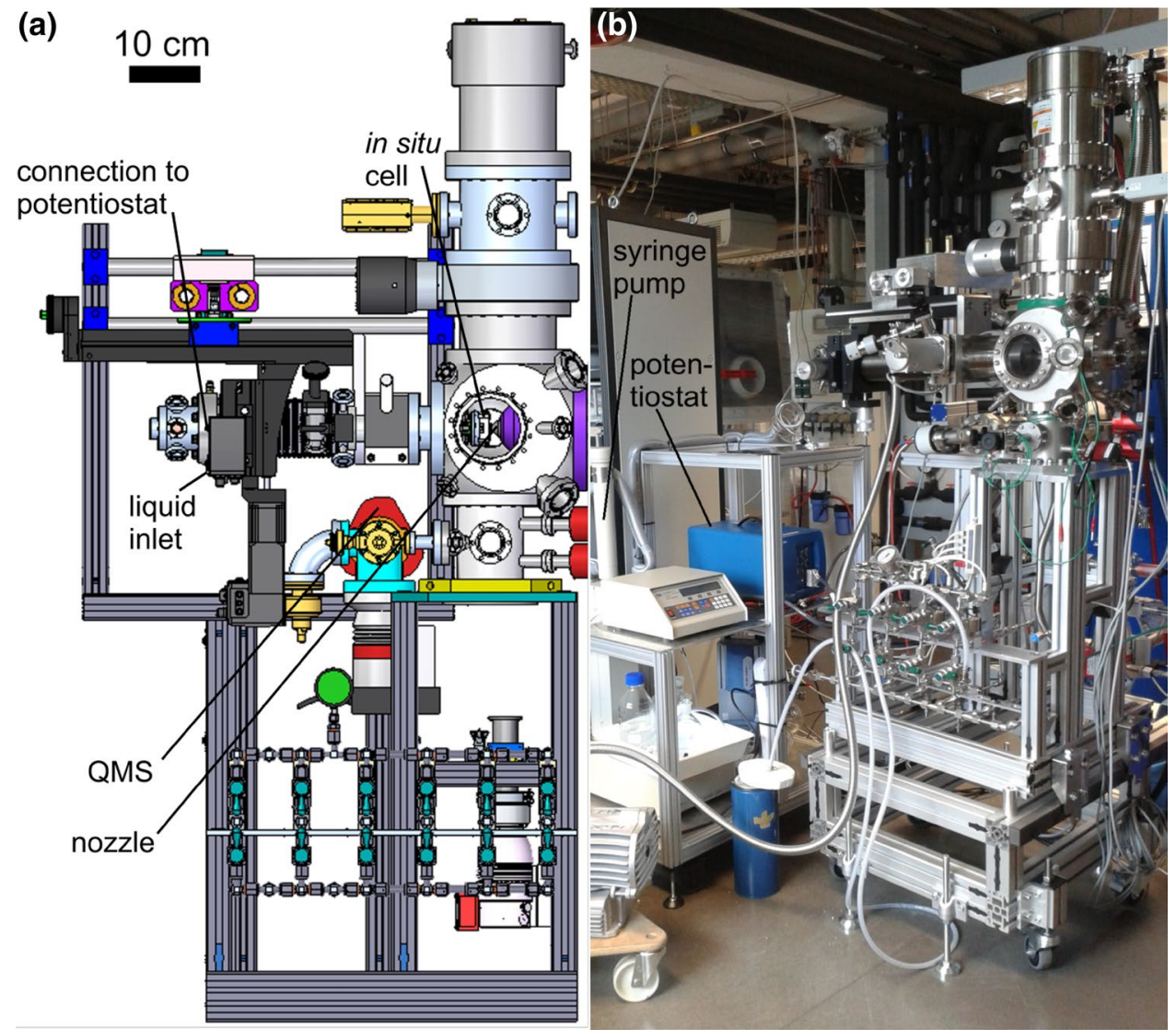

the chosen pass and excitation energies, the corresponding resolution was between 0.2 and $0.8 \mathrm{eV}$, with lower excitation and pass energies yielding higher resolutions. Core lines of the different materials were measured in surface-sensitive modes of different information depths. In the most surface-sensitive mode, the information depth is below $1 \mathrm{~nm}$. The exact measurement conditions will be detailed in the respective manuscript sections. All spectra were calibrated by measuring the Fermi edge after each core level scan and a corresponding rigid shift of the core levels, which is especially suitable for metallic samples.

For all O K-edge NEXAFS measurements, the photon energy was smoothly varied across the absorption edge by a continuous movement of the monochromator. Usually, both Auger and total electron yield (AEY and TEY) were collected. The AEY can be measured via the electron spectrometer at a fixed KE of the registered electrons. We used a KE of $385 \mathrm{eV}$ to partly suppress the contribution of gas-phase oxygen and water [30]. For the Mn L-edges, we used a KE of $500 \mathrm{eV}$. The used pass energy and further measurement details will be given in the respective manuscript sections. For the TEY collection, we used the Faraday cup of the first aperture of the differential pumping system and applied an accelerating voltage. In general, the probing depths of NEXAFS measurements are slightly higher than those of XPS measurements (AEY: 2-3 nm, TEY: 5-10 nm) [31].

\section{Two-Electrode Cell with Reservoir for Liquid [10]}

The two-electrode cell primarily designed for the in situ investigation of electrode surfaces during the oxygen evolution reaction (OER) is shown in Fig. 3a. The cell is composed of two core parts: the cell body and the lid. The cell body presents a recess area with a cylindrical cavity, which serves as reservoir for liquid water. The lid fixes an electrode assembly based on a Nafion® PEM onto the cell body. The counter and working electrode materials are applied onto either side of the PEM, e.g. by sputter-deposition, drop-casting, or physically attached porous carbon paper. Electrical contact of the WE and CE to the external potentiostat and grounding of the $\mathrm{CE}$ to the spectrometer is achieved through respectively connected sapphire screws. The leak-tightness of the cell is realized through O-rings. The direct contact of the membrane with the liquid water in the reservoir assures the needed hydration of the membrane for achieving good ion conductivity. Mounted onto a standard sapphire sample holder, this in situ cell can be introduced into the NAP-XPS 


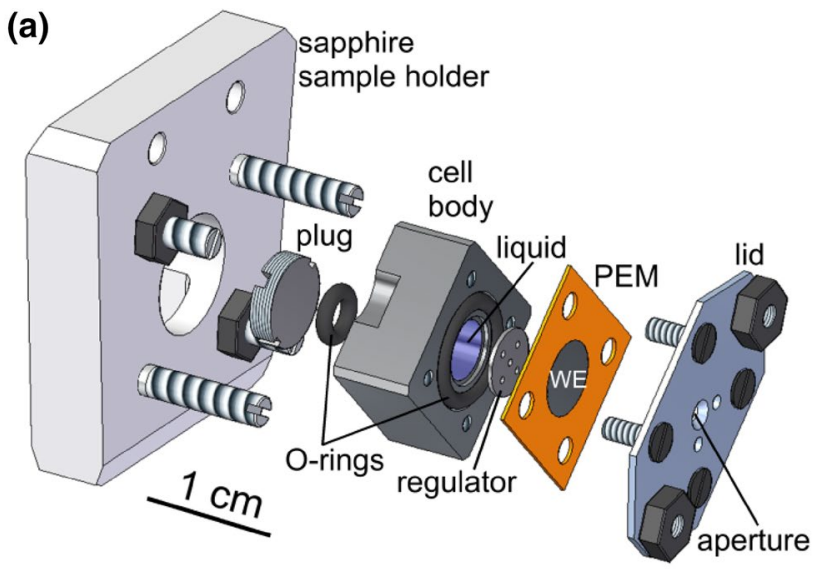

(b)

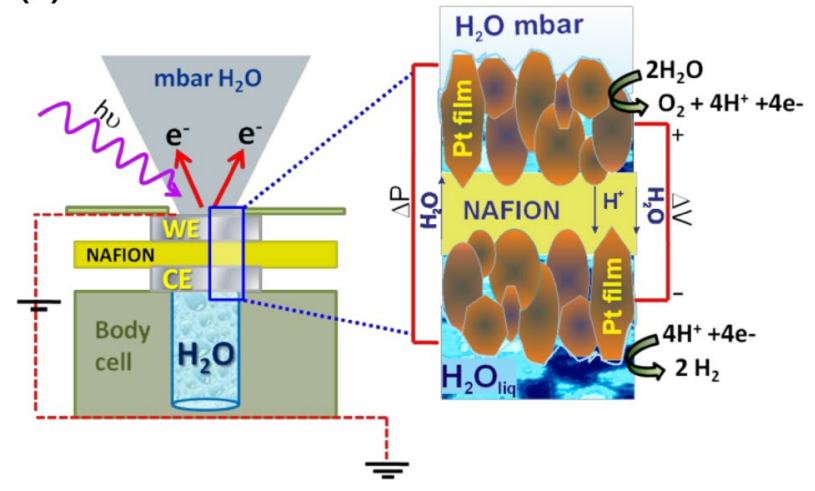

Fig. 3 a Construction model of the batch-type two-electrode cell for in situ X-ray photoelectron and absorption spectroscopy investigations mounted on a sapphire sample holder. During assembly, first the water regulator and the proton exchange membrane (PEM) with the working and counter electrode (WE and CE) are fixed on the cell body via the lid. Second, the cylindrical cavity is filled with liquid from the rear and subsequently closed with the plug. Finally, the cell body and lid are fixed onto the sapphire via the sapphire screws. b Schematic representation of the cell's working principle. The zoomed region illustrates that due to the pressure difference between the inner reservoir and the evacuated measurement chamber and due to the porosity of the WE and CE films, the liquid diffuses from the reservoir through the membrane, thereby opening the membrane channels, into the measurement chamber, where it generates a water pressure in the mbar range. b Reproduced with permission from John Wiley and Sons Ltd. from Ref. [10]

end station at the ISISS beam line at BESSY II/HZB [29]. The working principle of this cell is based on the water permeability of both the PEM and the employed electrode materials as illustrated in Fig. 3b: Due to the pressure difference between the liquid inside the cell body ( 1 bar) and the evacuated XPS chamber (0.01-0.1 mbar), water diffuses from the inner reservoir through the water permeable electrode assembly into the NAP-XPS chamber. Thereby, the electrode exposed to photons through an aperture in the lid is supplied with the reactant molecules. The electrode directly in contact with the liquid water functions as the $\mathrm{CE}$, whereas the electrode exposed to photons is the WE. By applying

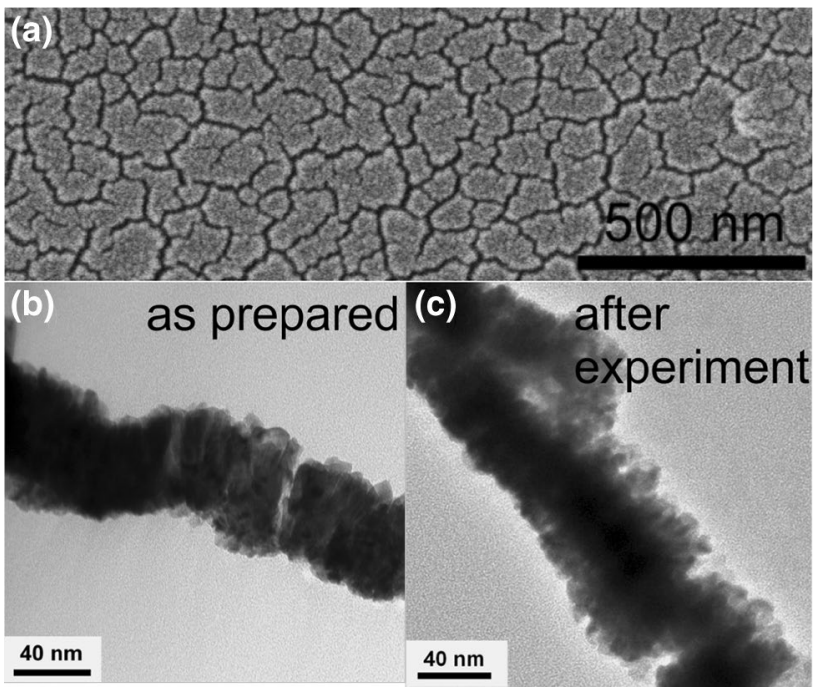

Fig. 4 a Scanning electron microscopy (SEM) image of a sputterdeposited Pt film on a Nafion ${ }^{\circledR}$ proton exchange membrane (PEM) recorded with an acceleration voltage of $1.5 \mathrm{kV}$ showing the mudcrack type structure of the electrode material ensuring water permeability. b, c Transmission electron microscopy (TEM) images of the sputter-deposited Pt film of $\mathbf{b}$ a freshly prepared film and $\mathbf{c}$ a film after in situ experiments recorded with an acceleration voltage of $200 \mathrm{kV}$. The TEM images show that the film consists of interconnected nanoparticles randomly interrupted by cracks. After experiment, the nanoparticles are less densely packed revealing the hydration process of the interface during the oxygen evolution reaction. a Reproduced from Ref. [12] with permission from the Royal Society of Chemistry. b, $\mathbf{c}$ Reproduced with permission from John Wiley and Sons Ltd. from Ref. [10]

chronoamperometry (CA) to the electrode system, this cell can be used to study oxygen-evolving surfaces in situ by XPS and NEXAFS.

This cell was first used to investigate the reactivity of sputtered Pt films as reported by Arrigo et al. in a previous publication [10]. To ensure the functionality of the cell system, we initially thoroughly characterized its components. Water permeability is achieved since Pt films sputter-deposited on Nafion ${ }^{\circledR}$ have a mud-crack type structure (see Fig. 4a). Electrical conductivity is attained since the Pt films are composed of interconnected nanoparticles (see Fig. 4b). Particularly in these experiments, the Pt film was approximately $50 \mathrm{~nm}$ thick. Thinner metal layers did not always result in a continuous film and some regions were found electrically disconnected by XPS. Representative high-resolution transmission electron micrographs (TEM) of the Pt film on the Nafion ${ }^{\circledR}$ before and after the in situ experiment are reported in Fig. 4b, c, respectively. In these TEM images, the characteristic morphology of the film is visible: The film is composed of differently densely packed agglomerates of nanoparticles that are interconnected but randomly interrupted by cracks. The film accommodates onto Nafion ${ }^{\circledR}$ according to the membrane's morphology, 
which gives rise to thickness variations as well as roughness. As shown in Fig. 4c, the Pt film after in situ anodic polarization presents areas of less densely packed nanoparticles on both the Nafion ${ }^{\circledR} / \mathrm{Pt}$ and $\mathrm{Pt} / \mathrm{H}_{2} \mathrm{O}$ interfaces corroborating a hydration process of the interface upon OER.

The chemical composition of the surface and near-surface region of a freshly prepared Pt film determined by XPS measurements with a probing depth of $0.5 \mathrm{~nm}$ is approximately 10 at\% O, 10 at\% Pt, and 80 at\% C. Hence, most of the $\mathrm{Pt}$ metal surface is covered with $\mathrm{C}$ originating from the sputter-coating procedure. Figure 5a shows that the analysis of surface-sensitive $\mathrm{C} 1 \mathrm{~s}$ and $\mathrm{O} 1 \mathrm{~s}$ spectra recorded during a preliminary sputtering experiment revealed the presence of $\mathrm{C}$ atoms in both $\mathrm{sp}^{2} / \mathrm{sp}^{3}$ configurations indicating the amorphous nature of the $\mathrm{C}$ deposit. Sputtering in a $10^{-4} \mathrm{mbar} \mathrm{Ar} /$ water atmosphere in the measurement chamber for approximately 15 min was effective to remove part of the $\mathrm{C}$ deposit. While sputtering for longer times (e.g. $53 \mathrm{~min}$ ) lead to a further reduction of the carbon coverage and introduction of $\mathrm{C}-\mathrm{O}$ species (components at $286.4 \mathrm{eV}$ and $532.4 \mathrm{eV}$ in the $\mathrm{C} 1 \mathrm{~s}$ and $\mathrm{O}$ 1s (Fig. 5a), respectively), it compromised the integrity of the film: Parts of the film were found electrically disconnected by XPS. More bulk-sensitive survey spectra of the as-prepared film, after $15 \mathrm{~min}$, and after $53 \mathrm{~min}$ of sputtering (Fig. 5b) revealed the appearance of $\mathrm{F}$ and $\mathrm{S}$ core levels originating from the Nafion ${ }^{\circledR}$ substrate. Exposure to air of the cleaned surface results in additional $\mathrm{C}$ deposition (Fig. 5a), hence ex situ cleaning would not be as effective. For this reason, before the in situ spectroscopic measurements, the film was sputter-cleaned for $20 \mathrm{~min}$ in a $10^{-4}$ mbar Ar/water atmosphere in the measurement chamber to remove $\mathrm{C}$ deposits from the surface and to maximize the exposed Pt surface area without compromising the integrity of the film. Further, to attain a robust Pt structure-function correlation, cyclic voltammetry was performed until electron transfer waves typical of Pt electrodes occurred, before water electrolysis was investigated during CA.

The major limitations of this cell are: (a) the rapid consumption of water, which causes the loss of membrane ion conductivity as well as desiccation of the metal film and loss of electrical conductivity; (b) the current collector of the WE is a $\mathrm{NiCr}$ wire across the aperture of the lid, which is insulated from the electrode. Thus only that part of the sample in electric contact with the wire will be under the applied potential and therefore it is not possible to evaluate precisely the active surface area which can change with time; (c) gases evolved at the $\mathrm{CE}$, in this case $\mathrm{H}_{2}$, but also left-over air bubbles from the membrane mounting process are trapped in the reservoir. These trapped gases exert a pressure on the membrane that soon causes (1) the metal film to break and (2) the $\mathrm{H}_{2}$ to transfer through the membrane as detected by the MS. Additionally, in a typical cyclic voltammogram (Fig. 6), we observe a potential shift of the faradaic processes typically
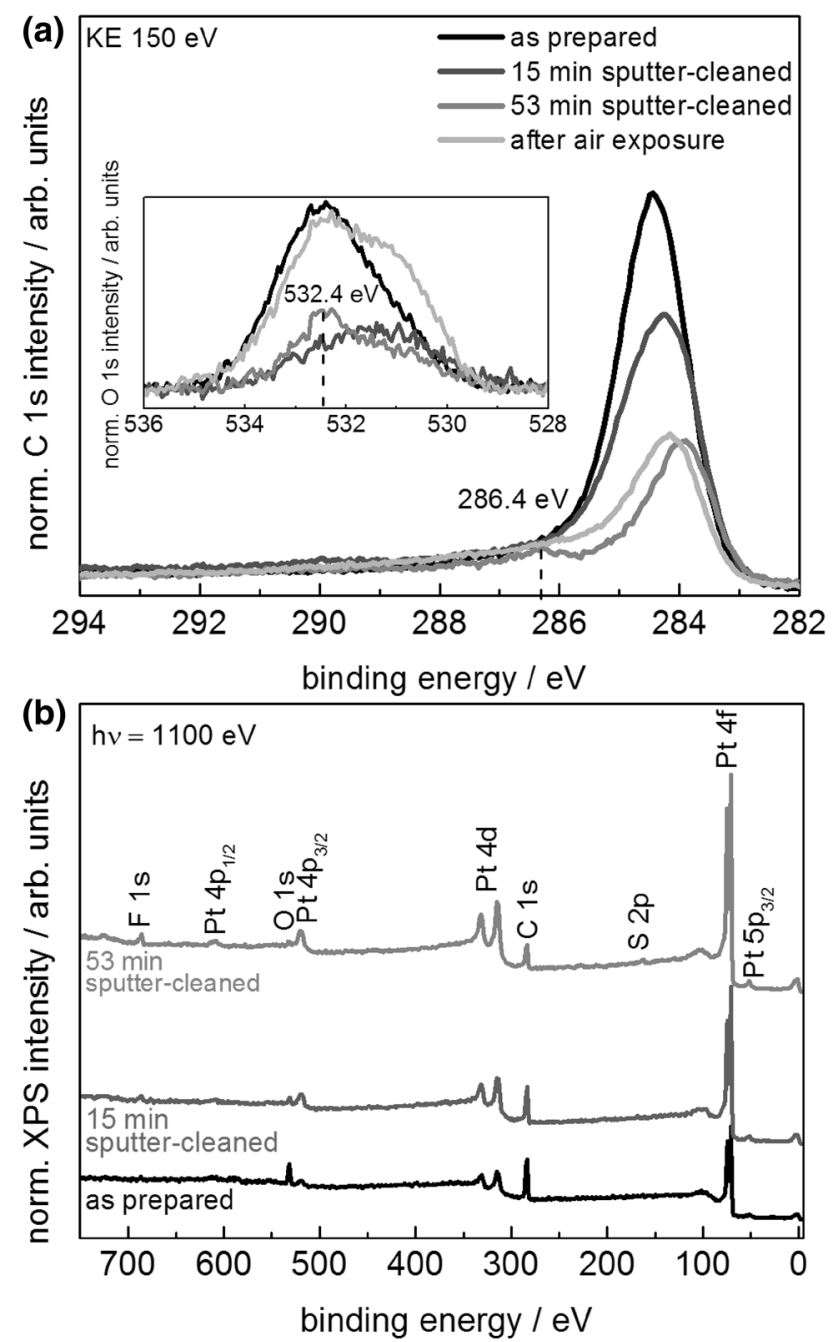

Fig. 5 a Normalized XPS C 1s spectra of a Pt film sputter-deposited on Nafion ${ }^{\circledR}$ measured in the two-electrode cell at open circuit potential (OCP) and $0.01 \mathrm{mbar}$ as prepared, after $15 \mathrm{~min}$, and after $53 \mathrm{~min}$ of sputter-cleaning $\left(10^{-4} \mathrm{mbar} \mathrm{Ar} /\right.$ water atmosphere with an acceleration voltage of $1.5 \mathrm{kV}$ and a current of $20 \mathrm{~mA}$ ), and after air exposure with a kinetic energy (KE) of the photoelectrons of $150 \mathrm{eV}$. The inset shows the respectively recorded normalized XPS O 1s spectra. The 15 min sputter-cleaning procedure already effectively reduces the $\mathrm{C}$ contamination of the surface. While the $53 \mathrm{~min}$ procedure further reduces the carbon contamination, it compromises the film integrity and some parts of the film were found electrically detached. Air exposure after the cleaning process results in additional carbon species. An ex situ cleaning procedure is therefore not suitable. b Respective XPS survey spectra of the as-prepared and the sputter-cleaned films. After 53 min of sputtering, the proton exchange membrane substrate $\mathrm{F} 1 \mathrm{~s}$ and $\mathrm{S} 2 \mathrm{p}$ core levels become visible

occurring on Pt, more markedly for those cathodic and anodic processes that occur below $0 \mathrm{~V}$ versus the Pt quasi reference electrode. We have verified that, despite the acidic nature of the Nafion ${ }^{\circledR}$ membrane, the use of liquid water as electrolyte, as compared to the use of $0.5 \mathrm{M} \mathrm{H}_{2} \mathrm{SO}_{4}$, leads to a potential range at which the HER occurs that is consistent 


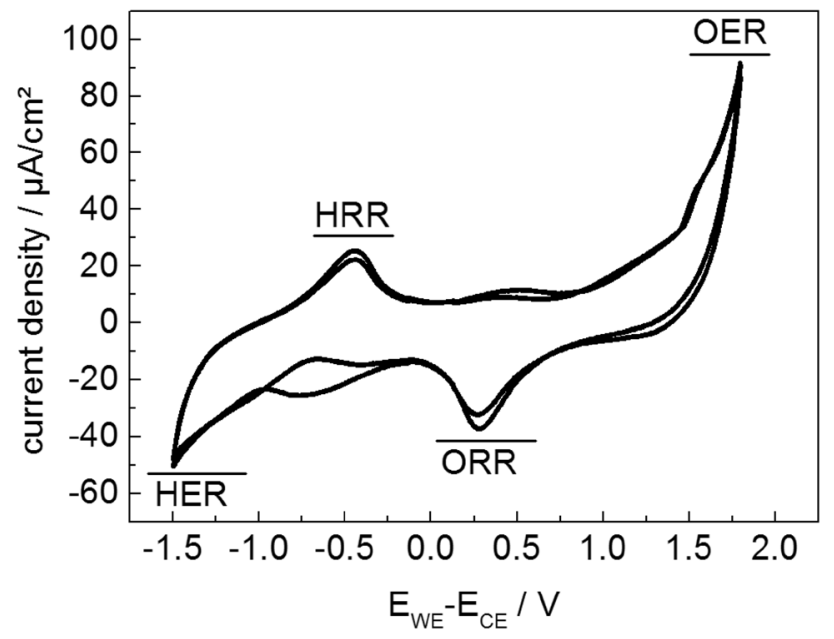

Fig. 6 Cyclic voltammogram $(100 \mathrm{mV} / \mathrm{s})$ obtained for a Pt80Pd20/ Nafion ${ }^{\circledR} / \mathrm{Pt} 80 \mathrm{Pd} 20$ electrode assembly using the two-electrode cell at room temperature and with a water pressure in the chamber of approximately $0.01 \mathrm{mbar}$

with the redox process in neutral $\mathrm{pH}$ conditions involving $\mathrm{H}_{2} \mathrm{O}$ molecules rather than hydronium species. We consider this as an effect of the slow proton transfer across the cell. The slow proton transfer leads to an accumulation of protons on the surface of the working electrode when functioning as oxygen-evolving catalyst and a depletion of protons with consequent increase of the $\mathrm{pH}$ when functioning as hydrogen-evolving catalyst, respectively. In addition, we have verified by using the sputtered Pt film with a standard bench scale electrochemical cell that, intrinsically, a twoelectrode configuration leads to a broadening of the redox waves and a shift of their potentials if compared to the same cell in a three-electrode configuration. Therefore, the comparison of the potentials measured with our system to values reported in literature is not possible. Regardless, the online detection of the gases and the current density obtained are the most relevant experimental observables to evaluate a robust structure-function correlation.

Apart from the discontinuity in the use of the cell, which requires frequent refilling with water, this cell behaves in a very reproducible way. By monitoring the Fermi level shape and shift (expected to be close to the applied potential), the current measured by the potentiostat (approaching the $\mathrm{mA}$ range), and the composition of the gas phase, we were able to evaluate whether the collected data were meaningful or affected by any of the technical issues listed above. Note that the presence of $\mathrm{F}$ and $\mathrm{S}$ during the in situ experiments confirms that the active electrolyte/Pt/water interface is probed.

In the following, we will discuss three case studies, in which we employed the two-electrode cell to monitor oxygen-evolving electrode surfaces in situ by XPS and NEXAFS. In this respect, we will be responsive both to

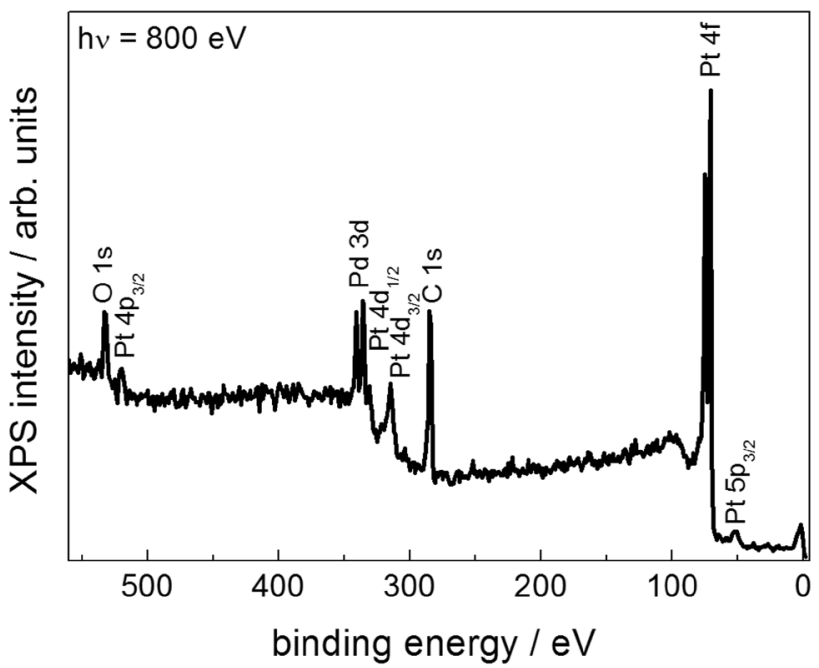

Fig. 7 XPS survey spectrum of a bimetallic Pt/Pd (80/20) film sputter-deposited on a Nafion ${ }^{\circledR}$ proton exchange membrane measured with the two-electrode cell at open circuit potential and $0.01 \mathrm{mbar}$. The survey spectrum is exclusively composed of the core levels pertaining to the electrode materials, carbon, and oxygen

the possibilities the cell offers and the necessary precaution when beam exposure affects the materials' chemistry. Despite its transient character and the pressure gap if compared to systems operating at atmospheric pressure, the instrumental development here reported has enabled us to cover unexplored conditions and thereby provide new insights into the OER.

Our first case discusses a bimetallic Pt/Pd (80/20) WE film sputtered on a Nafion ${ }^{\circledR}$ membrane and serves as showcase for the cell's ability to investigate oxygen- and hydrogen-evolving electrodes in situ. A sputtered monometallic Pt film was used as CE. An XPS survey spectrum of the Pt/Pd WE is shown in Fig. 7 and confirms that besides carbon and oxygen, no other contaminants are present on the surface.

The binding energy shift of the spectra when the WE is positively polarized is illustrated in Fig. 8 by $\mathrm{O} 1 \mathrm{~s}$ measurements at $\mathrm{OCP}$ and $+2 \mathrm{~V}$ and the corresponding Fermi edges. The spectra show that the positive polarization leads to a rigid shift of the spectra to higher binding energy. In addition, the shape and intensity of the $\mathrm{O} 1 \mathrm{~s}$ spectrum change as response to the positive polarization of the electrode and the corresponding change in the type and concentration of present oxygen species. To be able to compare the measurements at different applied potentials, we used the measured Fermi energy to determine the actual binding energy of present species $\left(\mathrm{BE}_{\text {actual }}=\mathrm{BE}_{\text {measured }}-\mathrm{FE}\right)$.

In an earlier report, Arrigo et al. identified the nature of the Pt species formed on a Pt film upon OER in situ and unveiled their role in the reaction mechanism [10]. Therein, the authors show that the OER-active sputtered $\mathrm{Pt}$ film is characterized by (1) a metallic $\mathrm{Pt}^{0}$ component, (2) a 


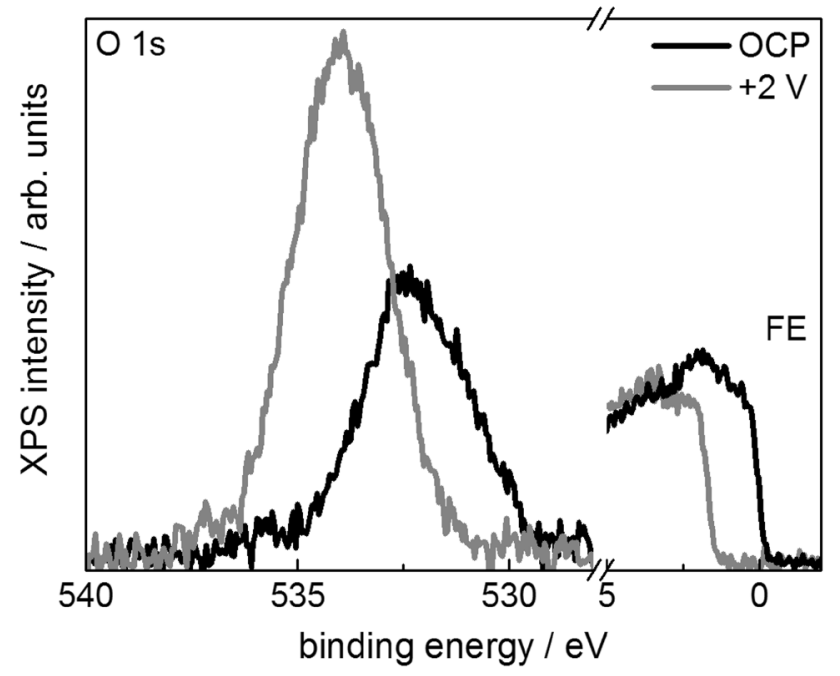

Fig. 8 XPS O 1s spectrum and corresponding Fermi edges (FE) of a bimetallic Pt/Pd (80/20) film sputter-deposited on a Nafion ${ }^{\circledR}$ proton exchange membrane measured with the two-electrode cell at 0.01 mbar at open circuit potential $(\mathrm{OCP})$ and $+2 \mathrm{~V}$ versus Pt quasi reference electrode, respectively

component $\mathrm{Pt}^{\delta+}$ due to metallic Pt electronically modified by subsurface $\mathrm{O}$ species (upshifted by $0.6 \mathrm{eV}$ compared to $\mathrm{Pt}^{0}$ ), and (3) $\mathrm{Pt}^{2+}$ species (upshifted by $1.3 \mathrm{eV}$ compared to $\mathrm{Pt}^{0}$ ). Upon the OER, the abundance of the $\mathrm{Pt}^{\delta+}$ species on the surface increases significantly, $\mathrm{Pt}^{2+}$ species are only a minor component of the in situ electrochemically oxidized Pt film under ambient pressure of 0.1-0.01 mbar, and $\mathrm{Pt}^{4+}$ species are not observed. Arrigo et al. show that the not observed formation of $\mathrm{Pt}^{2+}$ or $\mathrm{Pt}^{4+}$ is neither related to a protection effect exerted by the $\mathrm{C}$ impurities nor to the possible reduction of $\mathrm{Pt}$ by beam induced water radiolysis. Rather, $\mathrm{Pt}^{\delta+}$ species are the maximum oxidation states achieved under the $\mathrm{O}_{2}$ partial pressure used in this study. This observation strongly suggests that the formation of a stable oxide with $\mathrm{Pt}^{2+}$ species is not a necessary condition for the OER. In contrast, a clear correlation between OER activity and the abundance of $\mathrm{Pt}^{\delta+}$ was found. This component is described as clusters of Pt oxide at the steps of the rough Pt surfaces [32], which are able to dissociate water and turn it into $\mathrm{O}_{2}$ when the critical potential is reached. Since similar Pt $4 \mathrm{f}$ dynamics have been observed for the PtPd system of the present work, they are not explicitly shown here. Indeed, in this contribution, we focus on the $\mathrm{O}$ speciation as this will allow us to describe more in detail the ambient conditions realized in these experiments.

In this respect, Fig. 9 shows the $\mathrm{O} 1 \mathrm{~s}$ spectra recorded during polarization experiments of the $\mathrm{Pt} / \mathrm{Pd}$ film at $\mathrm{OCP}$; $-2 \mathrm{~V}$ (HER condition); and $+2 \mathrm{~V}$ (OER condition) versus $\mathrm{Pt}$ quasi RE. The $\mathrm{O} 1 \mathrm{~s}$ spectra are fitted with four components that describe the major changes over time. Note that in these experiments, a positive potential is applied to the

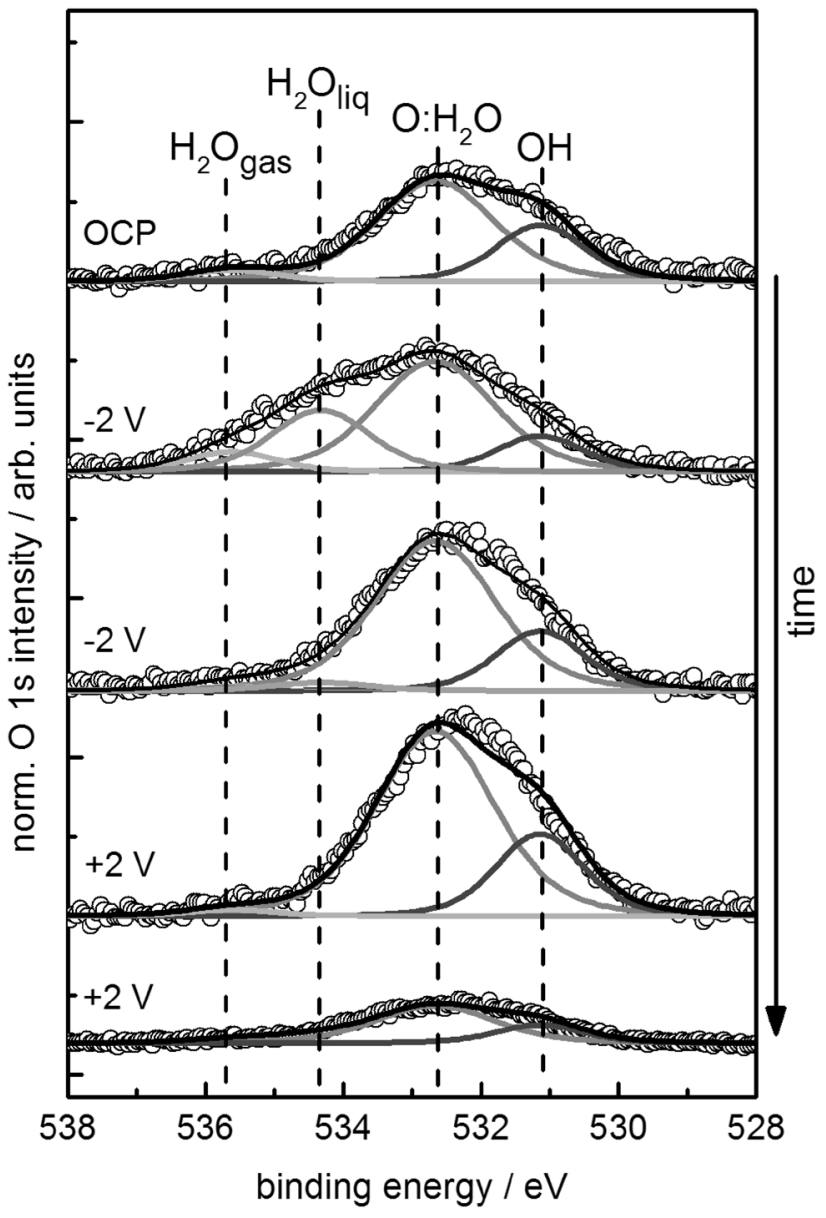

Fig. 9 XPS O 1s spectra recorded with the two-electrode cell during polarization of the sputtered $\mathrm{Pt} / \mathrm{Pd} 80 / 20$ film WE at potentials as indicated (kinetic energy (KE) of photoelectrons: $150 \mathrm{eV}$, exit slit setting: $111 \mu \mathrm{m}$, pass energy: $15 \mathrm{eV}$ ). From top to bottom the measurement time of each spectrum is: open circuit potential (OCP) (5 min); $-2 \mathrm{~V}(17 \mathrm{~min}) ;-2 \mathrm{~V}(47 \mathrm{~min}) ;+2 \mathrm{~V}(58 \mathrm{~min}) ;+2 \mathrm{~V}$ (98 min). The intensity of the Pd $3 p_{3 / 2}$ signal expected at $535 \mathrm{eV}$ is too low to be detected and was therefore neglected in the fitting

analyser cone to suppress the detection of gas-phase related photoelectron peaks.

The $\mathrm{O} 1 \mathrm{~s}$ spectrum of the film measured initially at $\mathrm{OCP}$ is described by two components: the lower binding energy component at $531.2 \mathrm{eV}$ is attributed to single $\mathrm{OH}$ species whereas the higher binding energy component at $532.6 \mathrm{eV}$ groups all the forms of dissociated and non-dissociated chemisorbed water such as single $\mathrm{OH}, \mathrm{OH}-\mathrm{OH}, \mathrm{O}-\mathrm{H}_{2} \mathrm{O}$ species adsorbed on Pt and Pd. Additionally, a small contribution from gas-phase water is visible even though the instrumental setting was adjusted to minimize this contribution. As the $\mathrm{Pt}$ film contains $\mathrm{C}$ impurities, $\mathrm{C}-\mathrm{O}$ species may also contribute to the components at $531.2 \mathrm{eV}$ and $532.6 \mathrm{eV}$ [10]. Afterwards, we polarized the WE at $-2 \mathrm{~V}$. To evaluate the stability of the oxygen species, we measured the $\mathrm{O} 1 \mathrm{~s}$ region twice at an interval of $30 \mathrm{~min}$. The first $\mathrm{O} 1 \mathrm{~s}$ spectrum 
measured at $-2 \mathrm{~V}$ polarization of the WE, shows a broad peak, which requires an additional component at $534.4 \mathrm{eV}$ as well as the gas-phase component at $535.7 \mathrm{eV}$. In the $\mathrm{O}$ 1s spectrum measured $30 \mathrm{~min}$ later at the same potential, however, these high binding energy components are reduced almost quantitatively. The appearance of the gas-phase signal at this potential indicates that the gas pressure is locally far above the background pressure of 0.01 mbar. The binding energy chemical shift of the component at $534.4 \mathrm{eV}$ is consistent with liquid water [8,33], which could be trapped within the pores of the metal film. Indeed, when a negative potential is applied, the transport of water is not only favoured by the pressure difference between the inner container and the evacuated chamber, but also by the applied potential, which induces the transport of $\mathrm{H}_{3} \mathrm{O}^{+}$species towards the WE.

Upon application of a potential of $+2 \mathrm{~V}$ at the WE, the system evolves oxygen and the water transport is driven to the opposite direction. At $+2 \mathrm{~V}$, the two components at $531.2 \mathrm{eV}$ and at $532.6 \mathrm{eV}$, due to single $\mathrm{OH}$ species and chemisorbed water, respectively, increase similarly to the case of pure Pt reported earlier [10]. After 80 min of measurement, however, the pressure measured in the XPS chamber decreased dramatically (from approximately 0.01-0.001 to $0.00001 \mathrm{mbar}$ ), simultaneously the current dropped, indicating that the water inside the reservoir was fully consumed and the cell stopped to work. Consistently, the O 1s XP spectrum measured in this condition also shows a significant decrease of the overall oxygen species as a result of the limited water supply.

The elemental composition of the surface and nearsurface region of the PtPd film during the in situ study as determined by XPS is reported in Table 1 . The atomic ratios reveal still the enrichment of the surface with carbon albeit the sputter-cleaning pretreatment. Upon cathodic polarization, we observe an increase of the $\mathrm{O}$ abundance $(\mathrm{O} / \mathrm{Pt}$ ratio increases) and a decrease of the $\mathrm{Pt}$ abundance $(\mathrm{C} / \mathrm{Pt}$ ratio decreases). This observation indicates that $\mathrm{O}$ and $\mathrm{H}_{2} \mathrm{O}$ related species are accumulating preferentially on the $\mathrm{Pt}$ exposed surface. Interestingly, the $\mathrm{Pd} / \mathrm{Pt}$ ratio also slightly decreases, which would suggest that $\mathrm{O}$ accumulates more

Table 1 Elemental composition of the surface and near surface region of a Pt/Pd 80/20 film $(\mathrm{KE}=150 \mathrm{eV}$ corresponding to $0.5 \mathrm{~nm}$ IMFP) at different potentials, determined by assuming a homogeneous model distribution

\begin{tabular}{llcll}
\hline Voltage (V) & $\mathrm{C} / \mathrm{O}$ & $\mathrm{C} / \mathrm{Pt}$ & $\mathrm{O} / \mathrm{Pt}$ & $\mathrm{Pd} / \mathrm{Pt}$ \\
\hline OCP & 7 & 5.6 & 0.8 & 0.4 \\
- 2 V (1st O 1s) & 6.9 & 9.4 & 1.4 & 0.3 \\
- 2 V (2nd O 1s) & 7 & 9.5 & 1.3 & 0.3 \\
+2 V (1st O 1s) & 6.3 & 13.3 & 2.1 & 0.3 \\
+ 2 V (2nd O 1s) & 45.4 & 13.3 & 0.3 & 0.3 \\
\hline
\end{tabular}

on Pd than on Pt, consistent with the less noble character of the former. Likewise, under anodic polarization water accumulates further preferentially on Pt. When the water in the cell is completely consumed, the $\mathrm{O} / \mathrm{Pt}$ ratio decreases significantly. Arrigo et al. discussed earlier [10] that the anodic polarization induces a small increase of the $\mathrm{C}-\mathrm{O}$ species, however, this contribution is a minimal part. These results demonstrate that most of the accumulated $\mathrm{O}$ is related to the interaction of water on $\mathrm{Pt}$ and takes part in the OER. Indeed, the nature of the deposited carbon is amorphous/graphiticlike, thus of sufficient chemical resistance on the one hand. On the other hand, it may be beneficial for holding the nanoparticles together and guaranteeing electrical conductivity.

Similar dynamics involving the oxygen species as observed in the XPS O 1s spectra were identified by NEXAFS at the $\mathrm{O}$ K-edge. In this case, from OCP the film was first anodically polarized to $+1.2 \mathrm{~V},+2 \mathrm{~V}$, and $+2.5 \mathrm{~V}$ versus CE quasi RE to induce the OER. Afterwards, the electrode was cathodically polarized to $-0.5 \mathrm{~V}$ and $-1.5 \mathrm{~V}$ to induce the HER. The O K-edge spectra in AEY (normalised to the edge jump) shown in Fig. 10a present resonances due to transitions from the $\mathrm{O} 1 \mathrm{~s}$ core level to the $\mathrm{O} 2 \mathrm{p}-\mathrm{Pt} 5 \mathrm{~d}$ (Pd 4d) hybridized unoccupied orbitals. The first resonance $\left(1 \mathrm{~s} \rightarrow \pi^{*}\right)$ is found with a maximum at $531.6 \mathrm{eV}$, which is attributed to $\mathrm{Pt}-\mathrm{OH}$ species [34]. The resonance at $534 \mathrm{eV}$ could be ascribed to $1 \mathrm{~s} \rightarrow \pi^{*}$ transitions from CO impurities bound to $\mathrm{Pt}$ [34]. The broad feature at $540 \mathrm{eV}$ is due to transitions to the unoccupied $\sigma^{*}$ orbitals $\left(1 \mathrm{~s} \rightarrow \sigma^{*}\right)$ and is attributed to $\mathrm{OH}-\mathrm{OH}$ scattering [34]. Upon application of an anodic potential, the intensity of the resonance due to $\mathrm{OH}$ species originally centred at $531.6 \mathrm{eV}$ increases significantly and shifts slightly to lower energy $(531.2 \mathrm{eV})$ reaching a maximum at $+2.5 \mathrm{~V}$ (Fig. 10a). At this potential, we expectedly also observe the highest OER rate throughout the experiment (not shown). The difference spectrum of the OCP and $+2.5 \mathrm{~V}$ measurements (see Fig. 10b) shows more clearly that several resonances contribute to this low excitation energy peak. Upon cathodic polarization $(-0.5 \mathrm{~V})$, the intensity of the first resonance decreases again and shifts back to higher excitation energies. This trend is even more significant at more negative voltages $(-1.5 \mathrm{~V})$ when $\mathrm{H}_{2}$ evolution is more pronounced. At this voltage, the spectrum overlaps with the spectrum at OCP in the $1 \mathrm{~s} \rightarrow \pi^{*}$ region (see Fig. 10c), indicating a chemical reduction of the PtPd film. However, it appears evident that now the broad $1 \mathrm{~s} \rightarrow$ $\sigma^{*}$ resonance centred at around $540 \mathrm{eV}$ is more intense. It was discussed in literature that an $\mathrm{OH}$ carpet might be formed via hydrogen bonding over the surface and, as a consequence, the resonance enhances due to the long-range ordering attained by the H-bond network [34]. Indeed, the difference spectrum of the OCP and $-1.5 \mathrm{~V}$ measurements reported in Fig. 10c shows features found for liquid water in 

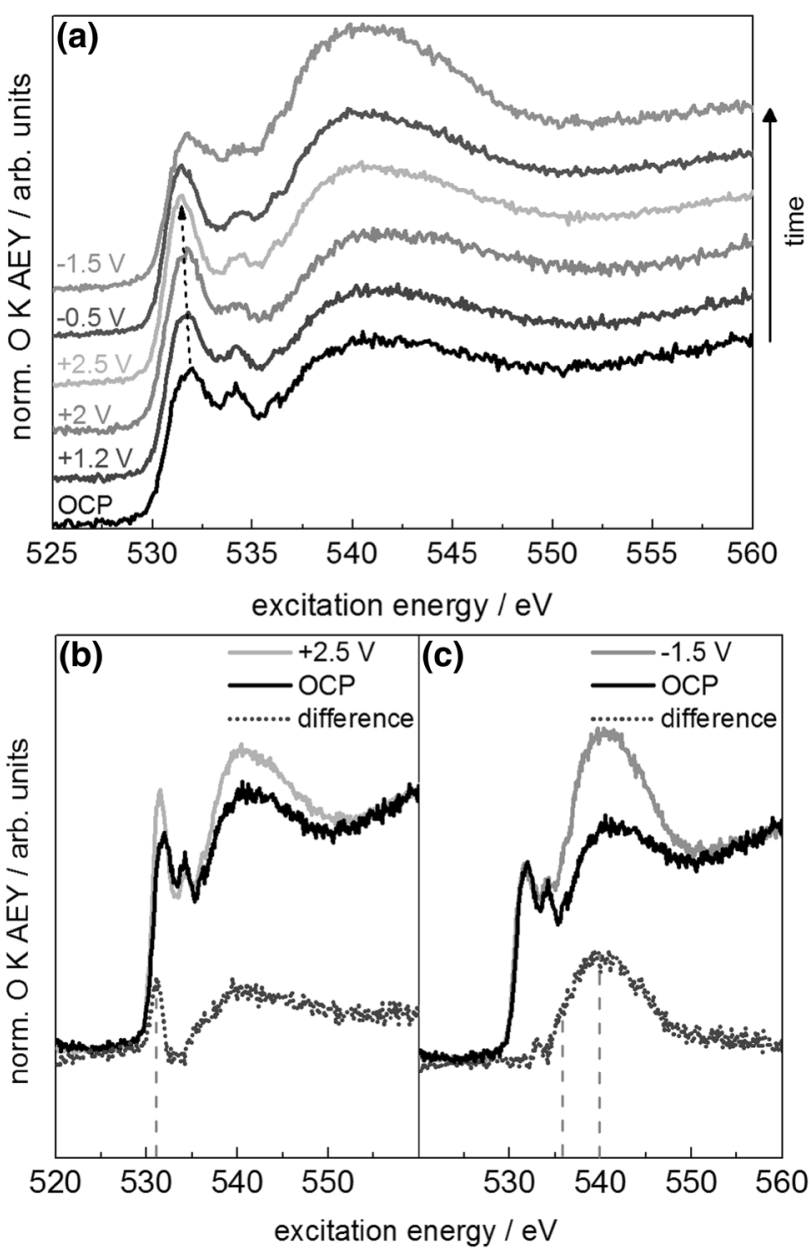

Fig. 10 O K-edge Auger electron yield (AEY) NEXAFS spectra recorded at 0.01 mbar with the two-electrode cell during polarization experiments of a PtPd 80/20 film sputtered on a Nafion ${ }^{\circledR}$ membrane a measurements were performed sequentially from bottom to top; $\mathbf{b}$ difference spectrum between $+2.5 \mathrm{~V}$ and OCP; $\mathbf{c}$ difference spectrum between $-1.5 \mathrm{~V}$ and OCP. OCP: open circuit potential, exit slit setting: $60 \mu \mathrm{m}$, pass energy: $100 \mathrm{eV}$

AEY O K-edge NEXAFS spectra reported in literature (the pre edge at $535.4 \mathrm{eV}$, the edge at $540 \mathrm{eV})[34,35]$.

In our second case study using the two-electrode cell, we show that the presented cell is highly flexible and can be adapted to study electrocatalysts based on metal nanostructures supported on carbon. To demonstrate this flexibility, we prepared IrOx/C-based electrodes via electrodeposition [36]. To this aim, we used carbon paper as substrate onto which we electrodeposited Ir from a $5 \mathrm{mM}$ $\mathrm{IrCl}_{3} \cdot 3 \mathrm{H}_{2} \mathrm{O}+0.5 \mathrm{M} \mathrm{KCl}$ solution. The working electrode was polarized at $0.55 \mathrm{~V}$ versus SCE until $2660 \mathrm{mC}$ had been transferred, resulting in a mass loading of $0.5 \mathrm{mg} /$ $\mathrm{cm}^{2}$. The electrodeposited Ir was subsequently oxidized by potential cycling with $100 \mathrm{mV} / \mathrm{s}$ between -0.2 and $+1 \mathrm{~V}$ versus SCE in $0.1 \mathrm{M} \mathrm{K}_{2} \mathrm{SO}_{4}$. An SEM image of the as-synthetized electrode is reported in Fig. 11a. The image
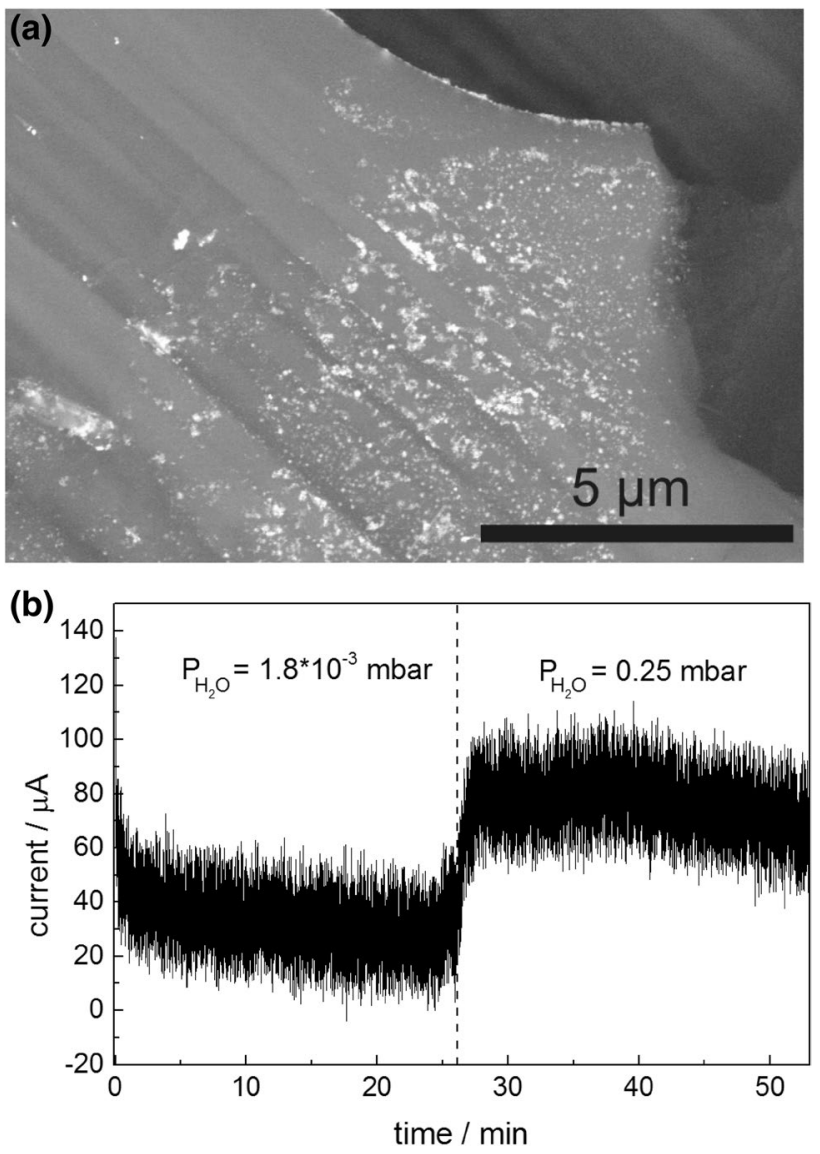

Fig. 11 a SEM image of the electrodeposited Ir on carbon paper recorded with an acceleration voltage of $15 \mathrm{kV}$ in backscattered electron mode. The bright spots correspond to the electrodeposited Ir phase supported on the carbon cloth. b Chronoamperometry signal recorded during electrode polarization at $+2 \mathrm{~V}$ in the two-electrode cell. An increase of the current is observed when the water pressure in the measurement chamber is raised from 0.0018 to 0.25 mbar by external water vapour dosage

shows the surface of the carbon rods forming the carbon cloth onto which the Ir particles are deposited (bright spots). The so prepared electrode was physically placed on top of the Nafion ${ }^{\circledR}$ membrane without any hot-pressing step and studied in situ.

The XPS results shown in Fig. 12 (survey) and 13 (core levels) indicate that the as-synthetized material is an Ir oxyhydroxide phase containing some $\mathrm{Cl}$ impurities. The broad Ir $4 \mathrm{f}$ peak (see Fig. 13d) with a full width at half maximum (FWHM) of $1.8 \mathrm{eV}$ could be considered the convolution of a main component of $\operatorname{Ir}(\mathrm{IV})\left(\operatorname{Ir} 4 \mathrm{f}_{7 / 2} \mathrm{BE}=61.7 \mathrm{eV}\right)$ and an additional component of $\operatorname{Ir}\left(\operatorname{Ir} 4 \mathrm{f}_{7 / 2} \mathrm{BE}=62.3 \mathrm{eV}\right)$ [37, 38]. Despite changes in the ligands coordinated to the Ir oxyhydroxide clusters, the Ir $4 \mathrm{f}$ of the Ir oxyhydroxide presents negligible changes in the electronic structure upon polarization. A detailed study dedicated to Ir-based electrodes will be presented in the next section. 


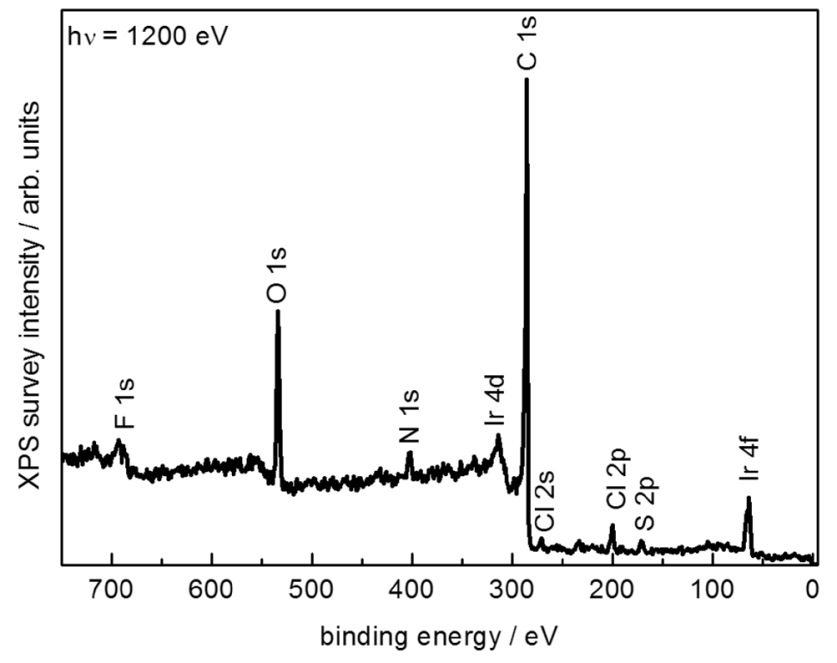

Fig. 12 XPS survey spectrum of the as-prepared $\mathrm{IrOOH}$ film on $\mathrm{C}$ paper recorded in the two-electrode cell at open circuit potential at 0.01 mbar, exit slit setting: $111 \mu \mathrm{m}$, photon energy: $1200 \mathrm{eV}$, pass energy: $20 \mathrm{eV}$

Noteworthy in this experiment, due to the high resolution of chemical states enabled by this technique, it was possible to observe the corrosion the carbon support suffers upon application of an anodic potential: The $\mathrm{C} 1 \mathrm{~s}$ peak intensity at higher $\mathrm{BE}$ than the graphitic component visibly increases (see Fig. 13b). This corrosion is a well-known limitation in the use of C-based electrodes for the OER. The absolute current obtained is low due to several factors: (1) the low loading of the active species, (2) the not intimate interaction between the solid electrolyte, (3) the electrode materials high resistance for the $\mathrm{H}^{+}$transport, and (4) the low $\mathrm{H}_{2} \mathrm{O}$ pressure generated in the evacuated chamber by the water transport through the Nafion ${ }^{\circledR}$ membrane. However, the current's response to the addition of 0.25 mbar $\mathrm{H}_{2} \mathrm{O}$ vapour pressure in the XPS chamber confirms the electrode activity (see Fig. 11b). Interestingly, the pores of the carbon support act as a trap for gas-phase $\mathrm{H}_{2} \mathrm{O}$ and $\mathrm{O}_{2}$ as well as possible $\mathrm{C}$ gaseous compounds resulting from the corrosion of the support as demonstrated by the gas-phase components appearing at higher binding energy in the $\mathrm{O} 1 \mathrm{~s}$ spectra in these measurements (see Fig. 13a). When we compare the two $\mathrm{O}$ 1s spectra recorded at $+2 \mathrm{~V}$ in 0.25 mbar $\mathrm{H}_{2} \mathrm{O}$ atmosphere, we see that a small variation of the chemisorbed phase is accompanied by a significant evolution of species in the gas-phase. Note that the second O 1s spectrum is recorded immediately after the first one showing a dynamic switch from a prevailing $\mathrm{C}$ corrosion to OER (intensity increases at higher binding energy, corresponding to gas-phase oxygen evolution). This observation suggests that, in principle, OER catalysts could be optimized such to be used directly in selective hydrocarbon oxidation.

Our final showcase for the two-electrode cell presents how beam effects on the sample can complicate the

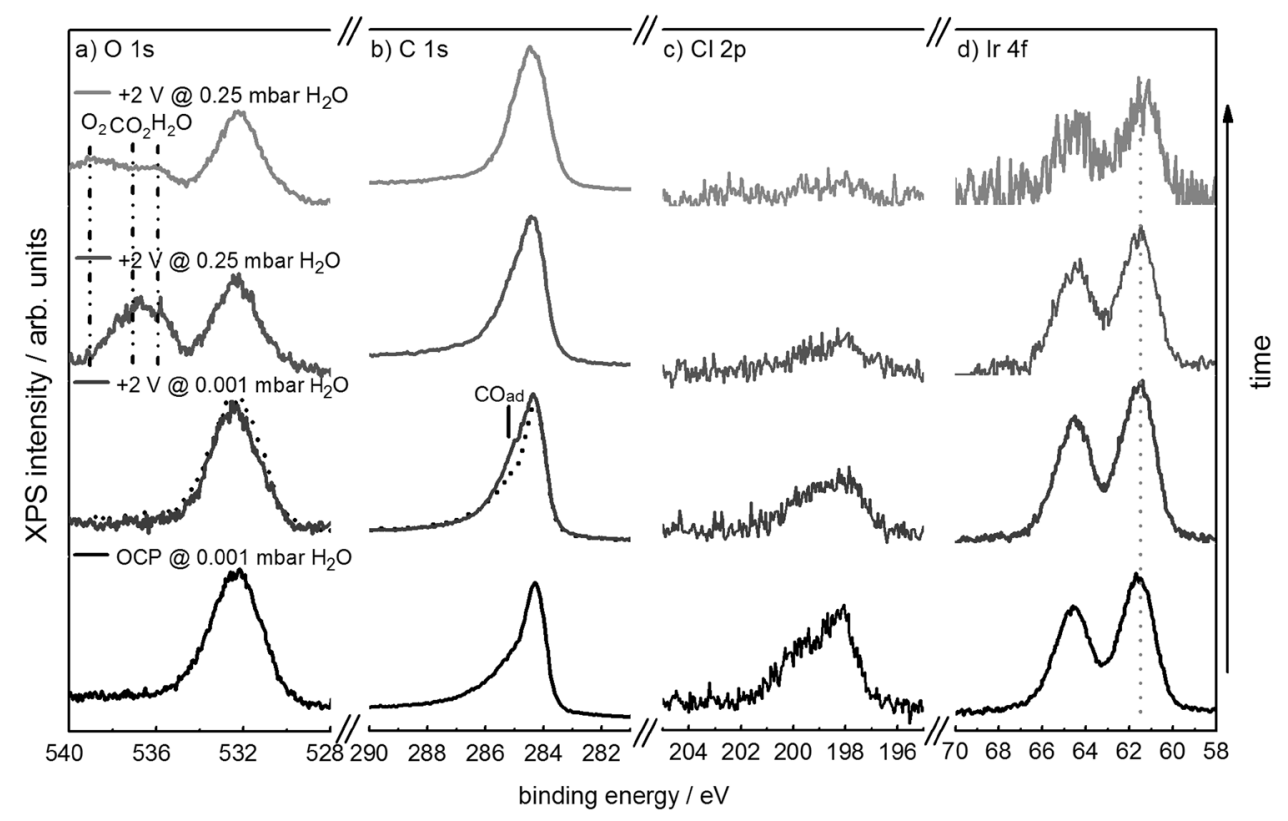

Fig. 13 XP spectra a O 1s; b C 1s; c Cl 2p; d Ir 4f of IrOOH electrodeposited on $\mathrm{C}$ recorded at open circuit potential (OCP) and during the oxygen evolution reaction (OER) at $+2 \mathrm{~V}$ at different water pressures. Due to the surface polarization and the application of $45 \mathrm{~V}$ at the cone of the electron analyser, the oxygen containing gas-phase components in the $\mathrm{O} 1 \mathrm{~s}$ spectrum are broad and thus unresolved. As a rule of thumb, in order of increasing BE, the following gas-phase species are assumed present in close proximity to the sample surface: $\mathrm{H}_{2} \mathrm{O}, \mathrm{CO}_{2}, \mathrm{CO}, \mathrm{O}_{2}$ (kinetic energy (KE): $600 \mathrm{eV}$, beam line exit slit setting: $111 \mu \mathrm{m}$, analyser pass energy: $15 \mathrm{eV}$ ). Note that the higher local pressure in the last two measurements results in a decrease of the signal-to-noise ratio for the $\mathrm{Ir} 4 \mathrm{f}$ spectrum (light grey line) 
measurement with this device. Earth-abundant transition metal oxides are currently under the spotlight of research to replace rare and expensive Ir-based electrocatalysts for the OER. This interest motivated us to investigate the suitability of this methodology for studying electrodeposited $\mathrm{MnOx}$, which is characterized by a diverse $\mathrm{OH}^{-} / \mathrm{O}^{2-}$ coordination chemistry as well as redox chemistry at reduction potentials of interest for the OER [39]. We again used carbon paper as substrate onto which we electrodeposited $\mathrm{MnOx}$ from a $20 \mathrm{mM} \mathrm{KMnO}_{4}$ solution following the procedure described by Zhao et al. [40]. The WE was polarized at $-0.85 \mathrm{~V}$ versus SCE until $510 \mathrm{mC}$ had been transferred, resulting in a mass loading of $0.3 \mathrm{mg} / \mathrm{cm}^{2}$. An XPS survey spectrum of the as-prepared MnOx on carbon paper is shown in Fig. 14. The SEM image in Fig. 15a shows a carbon fibre of the cloth with part of its surface uncovered, revealing preferentially oriented carved lines, whereas the Mn deposit appears with dendrite-like (brighter region) morphology. However, some of the electrodeposited Mn is very thick (not shown) and not well in contact with the carbon surface. The inhomogeneity in the deposition of manganese can cause problems when studying the structure-function relation. The following obstacles inhibiting the electrochemical performance were observed in this experiment series: (1) beam damage [41, 42], (2) low conductivity; (3) wetting problems.

A peculiarity of transition metal oxides is that their metal oxidation states generally can be more easily identified with NEXAFS than with XPS: The different oxides have clear fingerprint features in NEXAFS while their XPS core levels are more broadened by multiplet splitting and valenceshell recoupling in the core-excited state [31]. Therefore, we chose for the Mn case to concentrate on the Mn L-edges

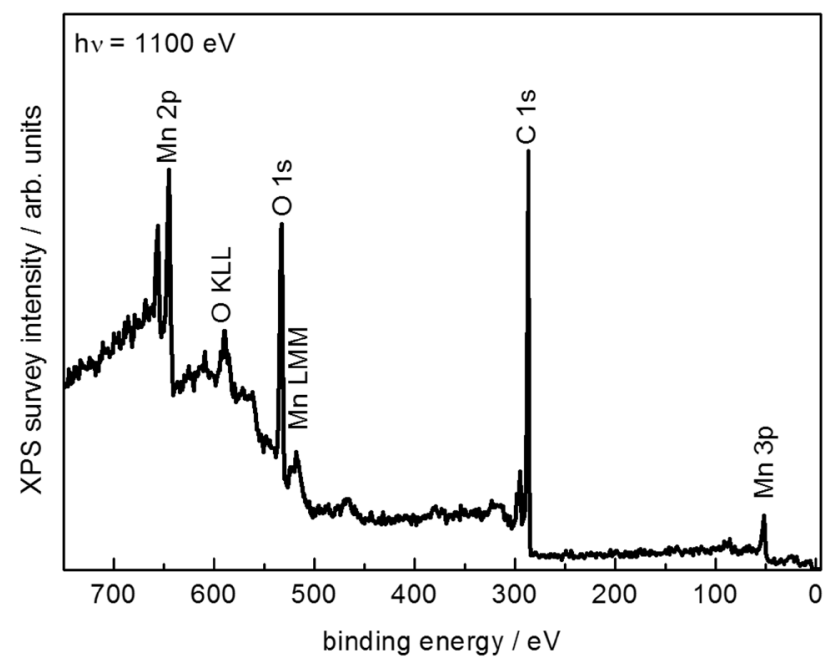

Fig. 14 XPS survey spectrum of the as-prepared $\mathrm{MnOx}$ film on $\mathrm{C}$ paper recorded in the two-electrode cell at open circuit potential at $0.01 \mathrm{mbar}$, exit slit setting: $111 \mu \mathrm{m}$, photon energy: $1100 \mathrm{eV}$, pass energy: $20 \mathrm{eV}$
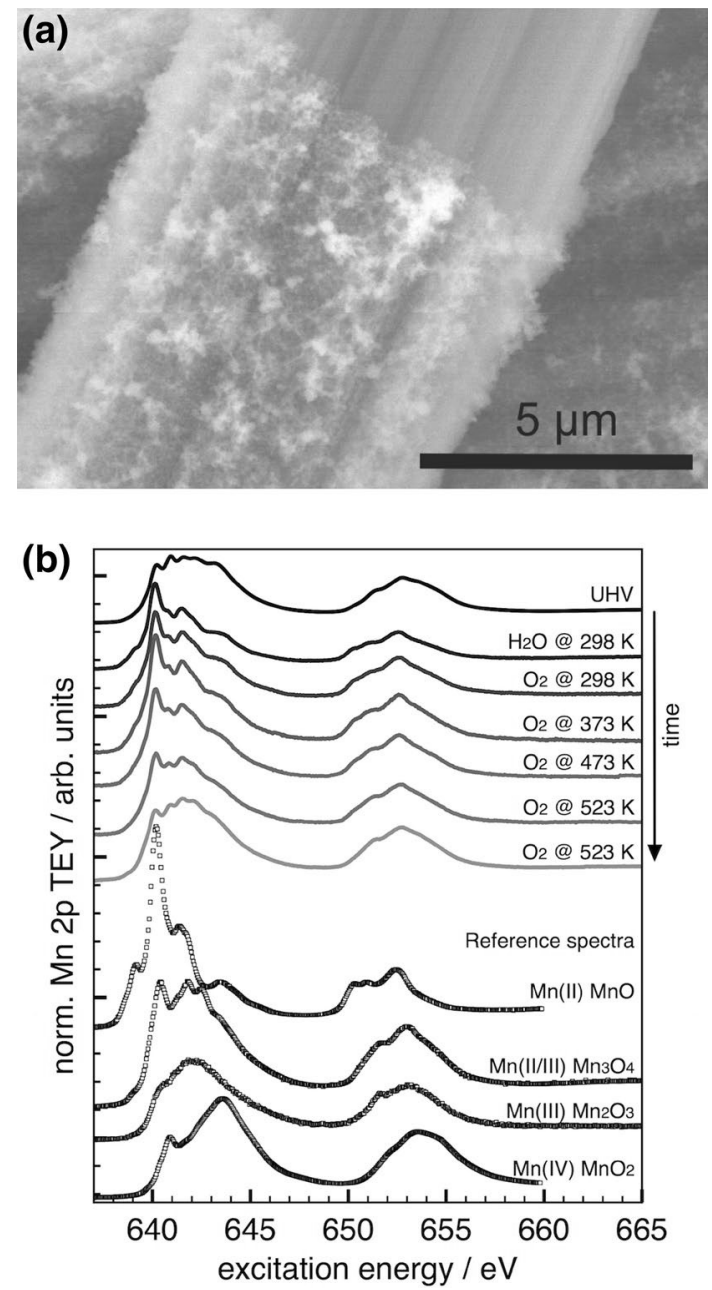

Fig. 15 a SEM image of electrodeposited $\mathrm{MnOx}$ on carbon paper. b From top to bottom, Mn L-edge NEXAFS spectra recorded subsequently under the specified conditions of temperature and reactive atmosphere at a pressure of 0.25 mbar and reference spectra of $\mathrm{Mn}(\mathrm{II}), \mathrm{Mn}(\mathrm{II} / \mathrm{III}), \mathrm{Mn}(\mathrm{III})$, and Mn(IV) oxides measured in UHV

NEXAFS spectra to determine present Mn oxidation states. Since NEXAFS is slightly less surface sensitive than XPS, we thereby compromise some surface sensitivity but gain more chemical insight.

In Fig. 15b, the Mn L-edges NEXAFS spectra of this sample are compared to reference spectra for $\mathrm{MnO}$ (Mn(II)), $\mathrm{Mn}_{3} \mathrm{O}_{4}(\mathrm{Mn}(\mathrm{II} / \mathrm{III})), \mathrm{Mn}_{2} \mathrm{O}_{3}(\mathrm{Mn}(\mathrm{III}))$, and $\mathrm{MnO}_{2}(\mathrm{Mn}(\mathrm{IV}))$ from commercially available manganese oxide powders after a required pretreatment (see Refs. [41, 43]). The freshly prepared sample is characterized by contributions from $\mathrm{Mn}$ (II), $\mathrm{Mn}(\mathrm{III})$ and Mn(IV) species (see Fig. 15b, UHV). However, we have observed instability of this material upon wetting in $0.25 \mathrm{mbar}_{2} \mathrm{O}$ and X-ray irradiation (Fig. $15 \mathrm{~b}, \mathrm{H}_{2} \mathrm{O}$ ) as opposed to the electrodeposited IrOOH (Fig. 13). Its full re-oxidation was not possible in situ at $0.25 \mathrm{mbar}_{2}$ at $523 \mathrm{~K}$, which can be concluded from the missing resonance 
at $644 \mathrm{eV}$ characteristic for the presence of Mn(IV) (see spectra in $\mathrm{O}_{2}$ atmosphere in Fig. 15b). These findings differ from the results obtained for samples calcined ex situ in air at $393 \mathrm{~K}$ [44]. We attribute this effect to beam damage, which is even more pronounced when water vapour is present in the chamber.

XPS measurements of the Mn $2 p$ core level at $+2 \mathrm{~V}$ polarization (not shown) indicated the expected shift of the peaks upon polarization, thus confirming that the sample was under the externally applied potential. The Mn L-edges NEXAFS spectra recorded for the fresh material at OCP and upon polarization under $10^{-5}$ mbar water pressure are reported in Fig. 16. A qualitative evaluation indicates that the electrodeposited material under OCP is already reduced and composed of mainly $\mathrm{Mn}$ (III) and $\mathrm{Mn}$ (II) species. Upon the application of $+2 \mathrm{~V}$ under low $\mathrm{H}_{2} \mathrm{O}$ pressure, only minor reduction due to radiation with $\mathrm{X}$-rays is visible, which is probably due to the poor wetting of the surface under this condition. The changes are more drastic when 0.25 mbar $\mathrm{H}_{2} \mathrm{O}$ is added into the evacuated chamber resulting in a significant reduction to $\mathrm{Mn}$ (II).

This result differs from recent published data on $\mathrm{MnOx}$ electrocatalysts performed in liquid environment, in which $\mathrm{Mn}(\mathrm{III}) / \mathrm{Mn}(\mathrm{IV})$ species were found during the OER $[45,46]$. Thus, it is evident that in this case our in situ

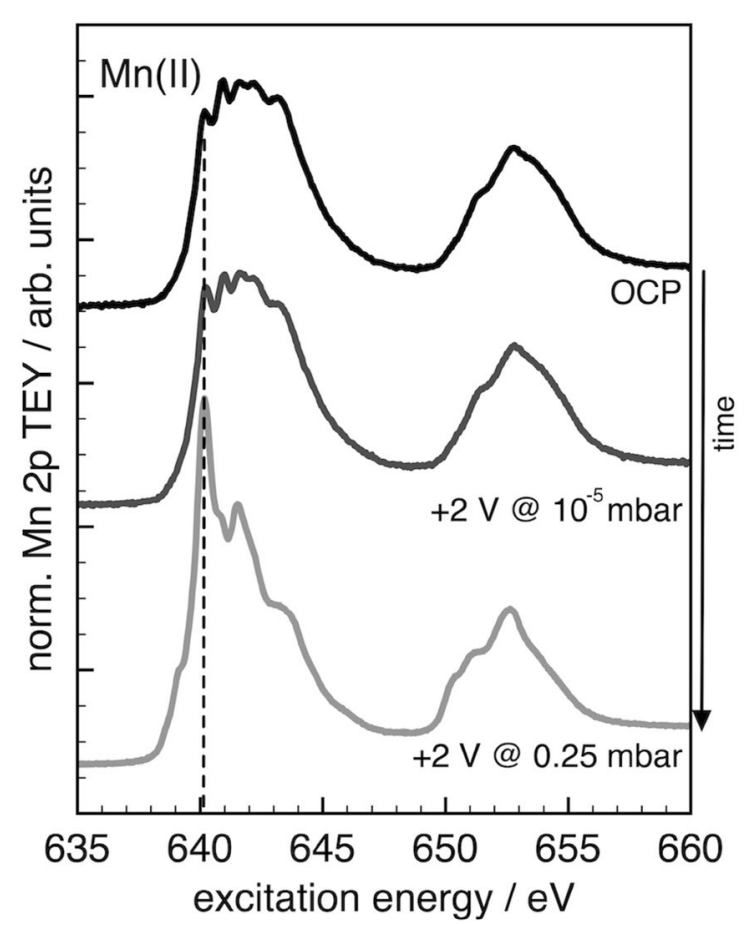

Fig. $16 \mathrm{Mn} \mathrm{L}$ edge spectra recorded during the in situ experiment for the electrodeposited $\mathrm{Mn}$ oxyhydroxide at: open circuit potential (OCP) and $10^{-5}$ mbar of $\mathrm{H}_{2} \mathrm{O}$ (black line); $+2 \mathrm{~V}$ and $10^{-5} \mathrm{mbar}$ of $\mathrm{H}_{2} \mathrm{O}$ (grey line); $+2 \mathrm{~V}$ and $0.25 \mathrm{mbar}_{2} \mathrm{O}$ (light grey line). The potentials are referred to the $\mathrm{Pt}$ quasi reference $\mathrm{CE}$ experiments were complicated: First, the measured spectra were highly affected by beam damage caused by the X-ray irradiation. Second, the poor wetting of the sample, which limits the water supply and the water turn over, inhibited the success of the in situ electrochemical experiments. Third, the poor conductivity of the electrodeposited samples might exacerbate the problem. This final showcase of the twoelectrode setup shows the pitfalls of this in situ technique. Hence, controlling the experimental conditions and sample preparation are of paramount importance.

\section{Three-Electrode Cell with Continuous Liquid Flow to Study the Oxygen Evolution Reaction [12]}

Once the concept had been established that PEM-based electrode assemblies were leak-tight and sufficiently stable upon $\mathrm{X}$-ray irradiation, we designed an in situ electrochemical cell with a continuous flow of electrolyte. The sustained electrolyte supply prevents the PEM from drying out, provides more stable measurement conditions, and renders longer measurement times possible. In addition, we modified the cell into a three-electrode system by integrating a micro reference electrode (RE) enabling direct comparison with bench electrochemical experiments.

The setup of the modified cell is shown in Fig. 17 by (a) a construction model and (b) a schematic cross section. In this configuration, the WE is again applied onto the membrane side facing the evacuated chamber for XPS and NEXAFS analysis. The $\mathrm{CE}$ ( $\mathrm{Pt}$ coiled wire) and the $\mathrm{RE}(\mathrm{Ag} / \mathrm{AgCl})$ are inserted from the side and rear parts of the cell, respectively, directly into the electrolyte stream and in close proximity to the Nafion ${ }^{\circledR}$ membrane. The electrodes connect to an external potentiostat that applies OER-relevant potentials while, simultaneously, XPS or NEXAFS are recorded.

Pfeifer et al. used this in situ electrochemical cell to investigate the reactivity of sputter-deposited metallic Ir films in the OER [12]. In contrast to the electrodeposited IrOx on carbon paper investigated with the two-electrode cell, in which Ir was already initially oxidised, this study focused on the early stages of Ir oxidation during the OER and the oxygen ligands forming on a metallic iridium substrate. In this contribution, we would like to review some important findings reported in [12] that prepare the ground for discussing advantages and disadvantages of the two cells presented here.

First, we confirm the comparability of the electrochemical results obtained with this three-electrode in situ cell with wet bench electrochemical experiments. To this aim, we recorded CVs of sputtered Ir films in $0.1 \mathrm{M} \mathrm{H}_{2} \mathrm{SO}_{4}$, see Fig. 18. In the three-electrode setup, it is no longer possible to only fill the cell with ultra-pure Milli-Q water as we had 

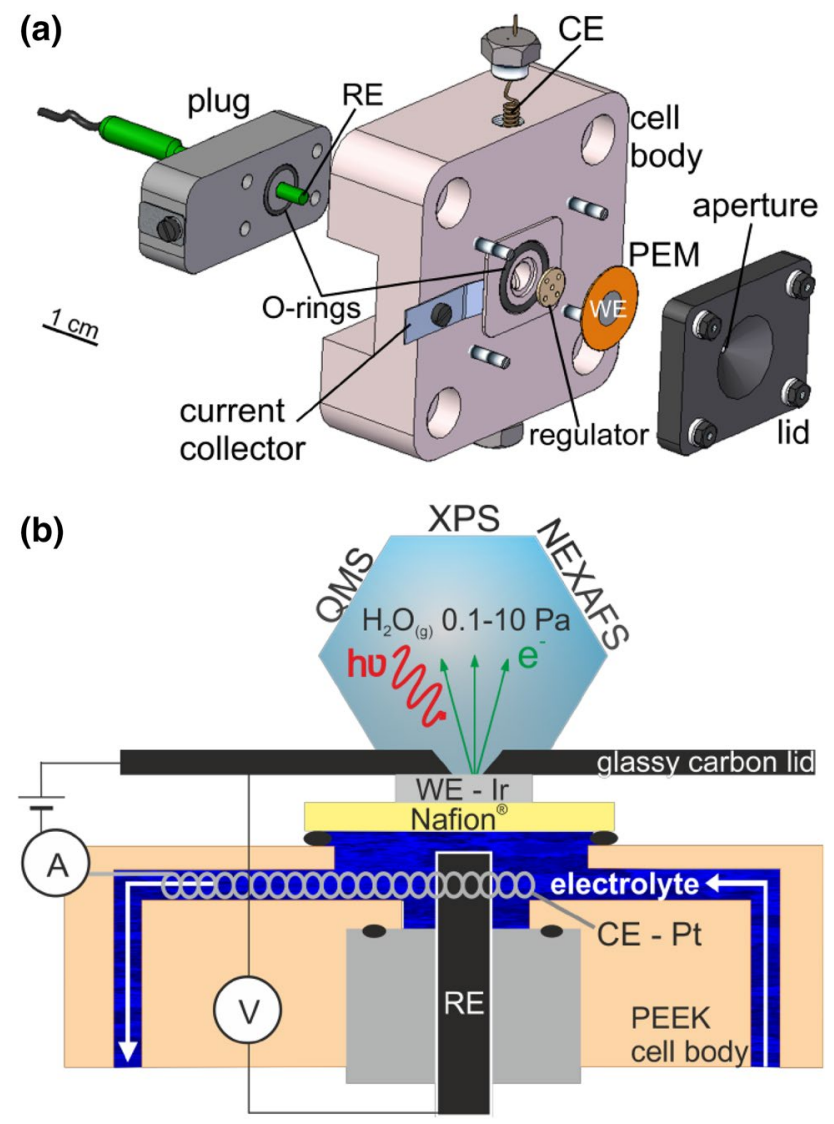

Fig. 17 a Construction model and b schematic cross section of the homemade three-electrode in situ cell with sputtered WE, Pt wire CE and $\mathrm{Ag} / \mathrm{AgCl} \mathrm{RE}$. For the assembly, all cell parts are fixed with the respective screws. The aqueous solution of the electrolyte is continuously supplied by means of an external syringe pump. The three-electrode cell has the same working principle as the two-electrode cell, described in detail in Fig. 3. b Reproduced from Ref. [12] with permission from the Royal Society of Chemistry

done for the two-electrode setup. The three-electrode cell requires the use of a liquid electrolyte to ensure the flow of ions between the RE and CE and the WE.

Indeed, the shape and peak positions of the oxidation waves as well as the OER onset are in accordance with previous literature reports on Ir [47]; e.g. in the anodic scan, the main oxidation wave of the material occurs at approximately $1 \mathrm{~V}$ versus SHE and there is a small oxidation wave at $1.4 \mathrm{~V}$ versus SHE before the OER onset at $1.5 \mathrm{~V}$ versus SHE.

In a next step, we considered possible beam damage of the samples. In earlier literature on XPS studies of Ir oxides for the OER, the electrode materials were first treated wet electrochemically and afterwards transferred into vacuum for XPS characterization. Upon irradiation exposure, active Ir oxides samples were found irreversibly deactivated for OER [48]. To address the beam sensitivity of our samples, we measured under low X-ray dose (13 mA ring current) and minimized the beam exposure time of the probed

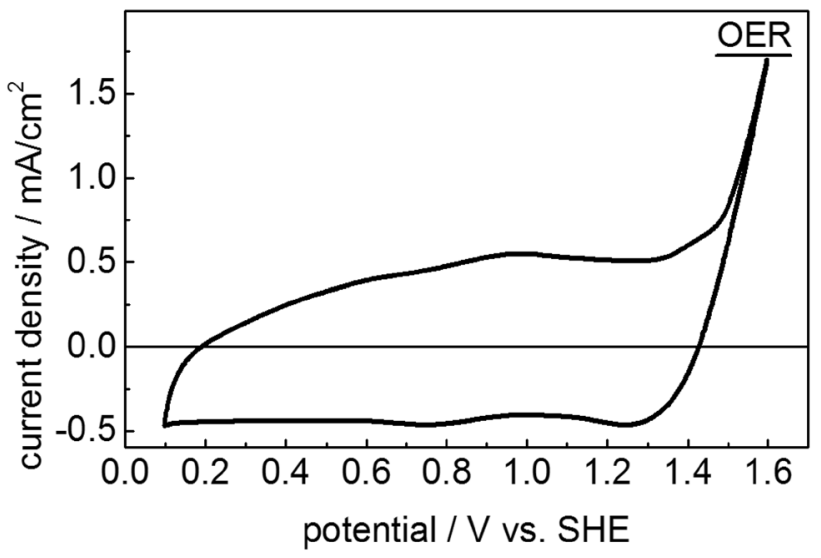

Fig. 18 Cyclic voltammogram of a sputter-deposited, $20 \mathrm{~nm}$ thick Ir electrode measured with the three-electrode in situ cell at $100 \mathrm{mV} / \mathrm{s}$ at $0.01 \mathrm{mbar}$ in $0.1 \mathrm{M} \mathrm{H}_{2} \mathrm{SO}_{4}$. Reproduced from Ref. [12] with permission from the Royal Society of Chemistry

region by choosing a new measurement spot for each set of measurement.

Finally, we determined the contribution of background signals to our measured spectra. Due to the maintained hydration of the film by the continuous supply of the electrolyte, the continuous flow cell suffers less from the problem of electrical disconnection of the films than the batchlike two-electrode approach. This improvement presented an opportunity to lower the metal film thickness down to $20 \mathrm{~nm}$. The adjustment of the film thickness, however, has spectroscopic implications. On the one hand, due to the surface sensitivity of XPS and NEXAFS and the mud-crack type structure of the sputtered Ir films, thinner films ensure that a larger amount of the spectroscopically probed material is in touch with the triple-phase boundary between electrolyte, electrode, and water and is therefore actively taking part in the reaction. On the other hand, the thickness reduction leads to a strong spectral contribution of the core levels and absorption edges from sulphate groups and carbon compounds originating from the liquid electrolyte and the Nafion ${ }^{\circledR}$. The presence of these additional signals makes the analysis of the O K-edge NEXAFS spectrum complicated since the oxygen signals originating from sulphur and metal (hydr)oxide compounds as well as water overlap. Thus, a controlled study of the nature of the species composing the $\mathrm{O} \mathrm{K}$-edge was necessary before we were able to discern the species involved in the activation of water and the OER at the metal surface from those belonging to Nafion ${ }^{\circledR}$ and the liquid electrolyte, respectively.

We initially investigated the $\mathrm{O}$ K-edge spectrum of a bare, uncoated Nafion ${ }^{\circledR}$ membrane mounted in the threeelectrode cell with a continuous flow of $0.1 \mathrm{M} \mathrm{H}_{2} \mathrm{SO}_{4}$ (see Fig. 19). From this investigation, we assessed the major contributions to the $\mathrm{O}$ K-edge spectrum from the Nafion ${ }^{\circledR}$ 


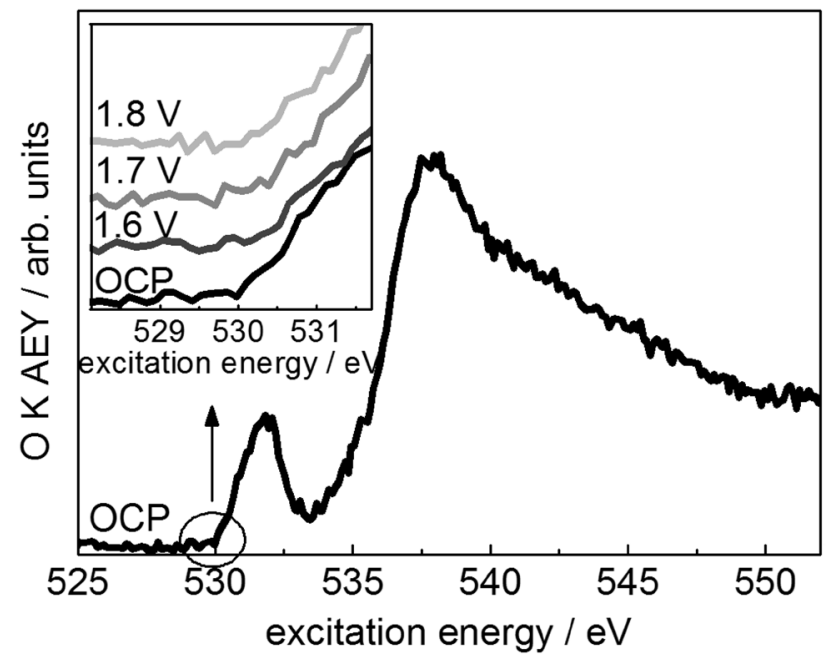

Fig. $19 \mathrm{O}$ K-edge of an uncoated proton exchange membrane (Nafion $\left.{ }^{\circledR} 117\right)$ measured with the three-electrode cell at open circuit potential (OCP) in Auger electron yield (AEY) at 0.01 mbar and with a continuous flow of $0.1 \mathrm{M} \mathrm{H}_{2} \mathrm{SO}_{4}$, beam line exit slit setting: $111 \mu \mathrm{m}$, kinetic energy: $385 \mathrm{eV}$, pass energy: $50 \mathrm{eV}$. Inset shows a zoom of the low excitation energy region recorded while the indicated OER-relevant potentials (vs. SHE) were applied. Figure adapted from Ref. [12] with permission from the Royal Society of Chemistry

"substrate" and the liquid electrolyte at excitation energies of $\approx 532 \mathrm{eV}$ and $\approx 537 \mathrm{eV}$. The former stems most likely from $1 \mathrm{~s} \rightarrow \pi^{*}(\mathrm{C}=\mathrm{O})$ transitions from carboxyl groups present on the membrane surface or in the electrolyte [49]. The latter originates from a convolution of $1 \mathrm{~s} \rightarrow \sigma^{*}(\mathrm{C}=\mathrm{O}$ and $\mathrm{C}-\mathrm{O})$ resonances of carboxyl groups [49] and ether groups of the Nafion ${ }^{\circledR}$ membrane as well as $\mathrm{O} \rightarrow \mathrm{S}$ transitions in sulphate species contained in the liquid electrolyte and the membrane itself $[50,51]$.

From previous reference experiments of highly OERactive $\mathrm{X}$-ray amorphous iridium oxides [37, 38], we knew that fingerprints of electrophilic $\mathrm{O}^{\mathrm{I}-}$ as well as of $\mathrm{O}^{\mathrm{II}-}$ species of iridium oxides are located in the $\mathrm{O}$ K-edge at 529 and $530 \mathrm{eV}$, respectively. Hence, we had to ensure that, upon polarization, the membrane/substrate contribution to the $\mathrm{O}$ K-edge spectrum does not change in this low excitation energy region. To this aim, we applied a range of OER-relevant potentials to the uncoated Nafion $®$ and monitored its $\mathrm{O}$ K-edge. The inset in Fig. 19 confirms that upon polarization, the energy window of interest remains unaffected; hence we validated that changes in this low energy region observed during our in situ studies of iridium oxides can be attributed to changes in the active catalyst material itself.

After these preliminary robustness checks of the system, we performed in situ investigations of oxygen-evolving iridium surfaces on a sputter-deposited metallic iridium film with a thickness of approx. $20 \mathrm{~nm}$. The film was first activated by $35 \mathrm{CV}$ cycles between +0.1 and $+1.6 \mathrm{~V}$ versus SHE, followed by transient experiments at OER-relevant

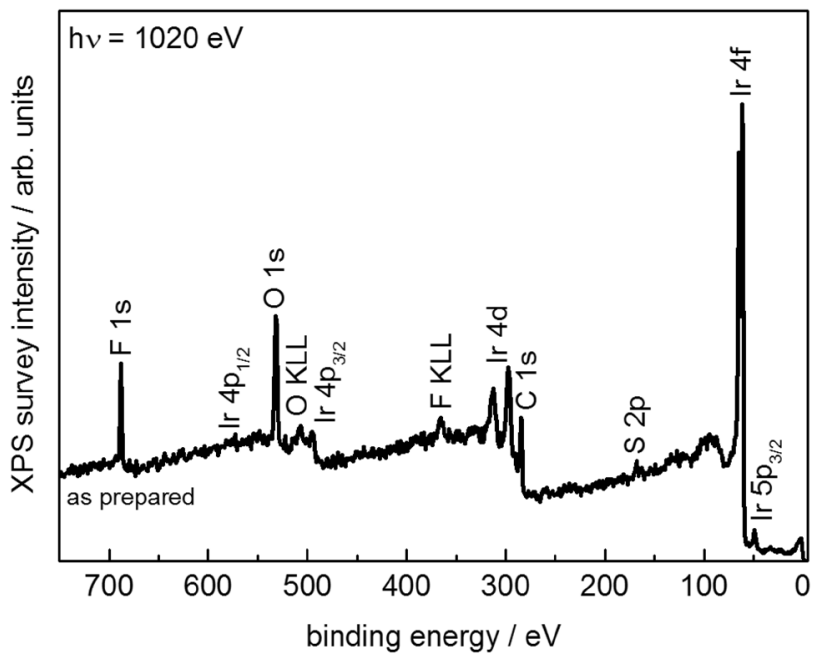

Fig. 20 XPS survey spectrum of the as-prepared Ir film recorded in the three-electrode cell at open circuit potential at $0.01 \mathrm{mbar}$ and with a continuous flow of $0.1 \mathrm{M} \mathrm{H}_{2} \mathrm{SO}_{4}$, beam line exit slit setting: $111 \mu \mathrm{m}$, photon energy: $1020 \mathrm{eV}$, pass energy: $20 \mathrm{eV}$. Adapted from Ref. [12] with permission from the Royal Society of Chemistry

potentials. Oxygen evolution was continuously monitored through the QMS unit connected to the NAP-XPS setup.

Figure 20 shows an XPS survey measurement of the as deposited Ir film on Nafion $\circledast$ mounted in the three-electrode cell at 0.01 mbar with a continuous flow of $0.1 \mathrm{M} \mathrm{H}_{2} \mathrm{SO}_{4}$. The survey only shows the core and Auger lines expected for the deposited Ir film (Ir) and the membrane (S, C, O, F). Please note that the $\mathrm{Ir} / \mathrm{C}$ ratio is considerably larger than the $\mathrm{Pt} / \mathrm{C}$ ratio observed above (compare Fig. 5). This observation shows that Ir is not as affected by carbon coverage during the deposition process as Pt. Therefore, in the case of Ir, we omitted the sputter-cleaning procedure.

While previous research on iridium had focused on the metal oxidation states [16, 52, 53], we were interested in the role of the oxygen ligands during the OER. To identify the oxygen ligands forming on oxygen-evolving iridium surfaces, we performed dedicated O K-edge NEXAFS investigations of the sample. Previous experiments had shown that the $\mathrm{O} \mathrm{K}$-edge region of iridium oxides is extremely sensitive to the presence of electrophilic $\mathrm{O}^{\mathrm{I}-}$ and $\mathrm{O}^{\mathrm{II}-}$ species [54]. Figure 21a shows the low excitation energy region of the in situ measured $\mathrm{O} \mathrm{K}$-edge at different applied potentials with fits using calculated spectra of $\mathrm{O}^{\mathrm{I}-}$ and $\mathrm{O}^{\mathrm{II}-}[37,38]$. We observe that during OER at $+1.7 \mathrm{~V}$ versus SHE indeed both electrophilic $\mathrm{O}^{\mathrm{I}-}$, centered at $529 \mathrm{eV}$, and $\mathrm{O}^{\mathrm{II}-}$, centered at $530 \mathrm{eV}$, are present. Especially for the electrophilic $\mathrm{O}^{\mathrm{I}-}$ species, we observe that the major contribution to the signal can be turned on and off by switching on and off the potential and, therewith, the OER. Hence, these species seem to be intimately linked to the OER activity of iridium oxides. The electrophilic nature and high reactivity of these 
Fig. 21 Low excitation energy regions of $\mathrm{O} \mathrm{K}$-edges of Ir-coated Nafion ${ }^{\circledR}$ samples, consecutively recorded a left to right and $\mathbf{b}$ bottom to top in the three-electrode cell with the indicated potentials versus SHE at 0.01 mbar and with a continuous flow of $0.1 \mathrm{M} \mathrm{H}_{2} \mathrm{SO}_{4}$, beam line exit slit setting: $111 \mu \mathrm{m}$, pass energy: $50 \mathrm{eV}$. c Normalized $\mathrm{O}^{\mathrm{I}-}$ and $\mathrm{O}^{\mathrm{II}-}$ concentrations determined from fit of low excitation energy region of O K-edge in b over QMS oxygen ion current. Adapted and reproduced from Ref. [12] with permission from the Royal Society of Chemistry

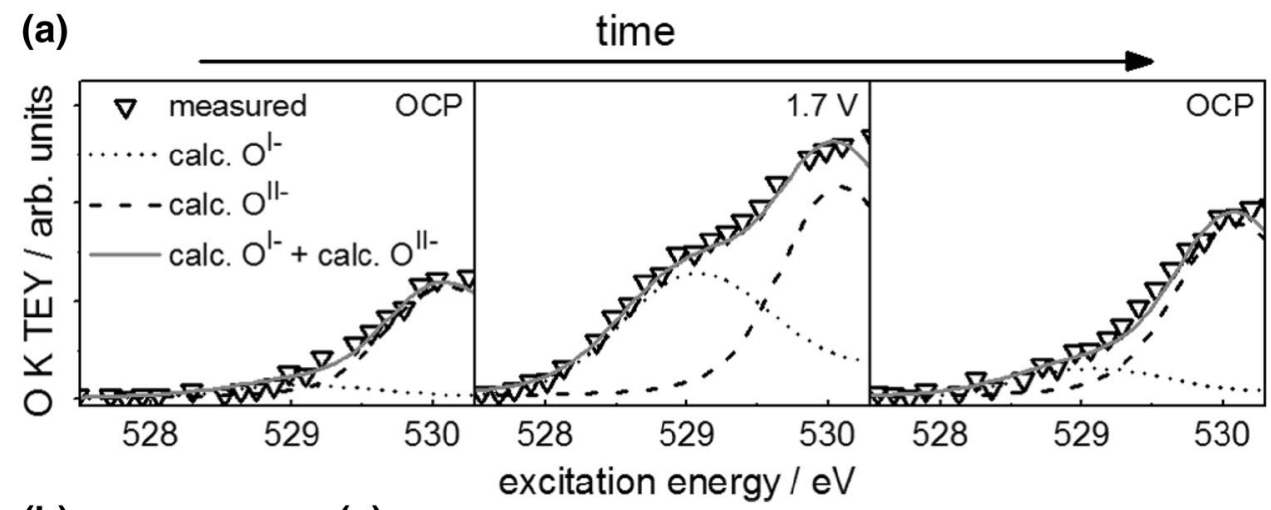

(b)
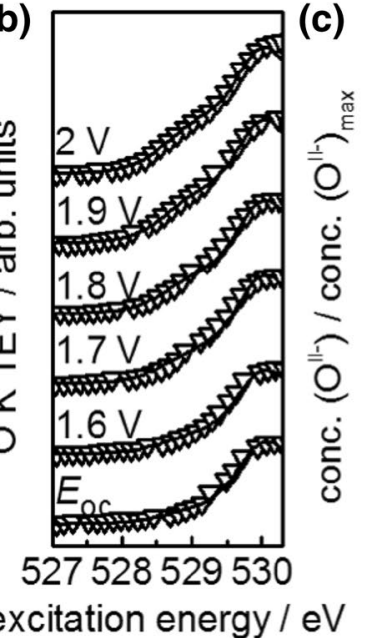

excitation energy / eV

species was previously confirmed by their ability to oxidize $\mathrm{CO}$ to $\mathrm{CO}_{2}$ at room temperature [54].

To test for a structure-function correlation between the abundance of reactive $\mathrm{O}^{\mathrm{I}-}$ species and oxygen formation, we consecutively increased the potential applied to the iridium electrode and analysed both the low excitation energy region of the $\mathrm{O} \mathrm{K}$-edge and the amount of oxygen formed. Figure 21b shows the measured O K-edges and the fit envelopes obtained from fitting the low excitation energy region of the measured with the calculated spectra for $\mathrm{O}^{\mathrm{I}-}$ and $\mathrm{O}^{\mathrm{II}-}$. Figure $21 \mathrm{c}$ shows the linear correlation between the amount of oxygen formed and the concentration of electrophilic $\mathrm{O}^{\mathrm{I}-}$ species. Noteworthy, while we were able to clearly follow the surface oxidation of the sample via the characteristic signals in the O K-edge NEXAFS, the Ir 4f spectra [12] hardly changed upon polarization showing that the bulk of the material remained mainly in its initial metallic state. These results indicate that the property making iridium oxides such unique OER catalysts is not their ability to form high valence cations, but their capacity to accommodate oxygen anions of formal oxidation state I-.

While a link between the presence of electrophilic $\mathrm{O}^{\mathrm{I}-}$ species and increased OER activity had already been suggested based on observations of reference measurements and CO titration [54], only by performing these in situ

investigations of an iridium electrode during the OER, a direct structure-function relationship between the electrophilic $\mathrm{O}^{\mathrm{I}-}$ species and the OER could be established [12]. This achievement underlines the potential of this threeelectrode in situ XPS and NEXAFS electrochemical cell to investigate energy conversion processes. This study has shed light onto the OER over IrOx catalysts, showing that not only a bulk oxide phase can activate $\mathrm{H}_{2} \mathrm{O}$ and turn it into $\mathrm{O}_{2}$, but also a predominantly $\operatorname{Ir}^{0}$ film with surface Ir oxide species can catalyse this reaction. This finding indicates the molecular or cluster-like character of the active Ir-O species.

\section{Discussion}

Providing a unified concept of the OER was attempted already early on by Trasatti [55]. Due to the increasing relevance of water electrolysis in energy research, this subject is currently being revisited with the aid of newly developed surface-sensitive in situ methodology. In our group, we aim to contribute to unveiling the reaction mechanism of the OER using a combination of surface-sensitive soft X-ray and electron-detection-based techniques. XPS is particularly useful for research in electrochemistry because it enables a contact-free probe of the electrochemical potential [6]. In 
principle, by looking at the core level shift and FWHM as functions of the potential, it is possible to describe the electrical double layer [33] and the modification the double layer undergoes as the potential is increased towards the intrinsic over-potential for the OER. This feature enables us to understand interfacial phenomena that lead to the high overpotential observed in all known active materials. However, the analysis of the XPS O 1s core level is often complicated due to the convolution of the different specifically chemisorbed oxygen species on the electrode surface (which are at the applied potential) and molecules of the solvent ions (which are at a different potential).

Recently, by analysing the broadening of the liquid water component in the $\mathrm{O} 1 \mathrm{~s}$ spectrum, the potential profile across the electrical double layer and the diffuse layer have been described [33]. In our experiments, the film of liquid water is much thinner than in the experiments reported in [33], where the $\mathrm{O} 1 \mathrm{~s}$ is dominated by the water component. Thus, we are more sensitive to specifically chemisorbed surface species on the electrode, which account for the catalytic properties of the electrode, but lack information about the electrolyte. Regardless, absorption spectroscopy at the O K-edge for the case of Pt (Fig. 10) has shown the presence of a thin layer of liquid water, which substantiates our findings. The quantitative analysis in Table 1 indicates that the dynamics of the oxygen species take place on the Pt surface and near-surface region. The surface chemistry scenario evidenced by our in situ study, however, was very different from the one seen over polycrystalline $\mathrm{Pt}$ foil after liquid electrolysis in $\mathrm{H}_{2} \mathrm{SO}_{4}$, [56] in which $\mathrm{Pt}^{2+}$ species and $\mathrm{Pt}^{4+}$ species dominated the topmost surface layer. Pioneering work $[57,58]$ postulated the formation of $\mathrm{PtO}_{2}$ phase and its transition into instable $\mathrm{PtO}_{3}$ before OER takes place. Our in situ study, however, shows that the active state of $\mathrm{Pt}$ is indeed a $\mathrm{Pt}^{\delta+}$ species stable under OER, whereas $\mathrm{Pt}^{2+}$ species are present in lower amount but also increasing in concentration with increasing anodic potentials. $\mathrm{Pt}^{\delta+}$ is a metallic $\mathrm{Pt}$ species electronically modified by $\mathrm{O}$ atoms in the subsurface, which is described as clusters of Pt oxide at the steps of the rough Pt surfaces [32]. $\mathrm{Pt}^{\delta+}$ is able to coordinate water and eventually turns it into $\mathrm{O}_{2}$. It appears evident that due to the low water chemical potential of our experiments, the surface is quenched in this $\mathrm{Pt}^{\delta+}$ oxidation state while further oxidation is prevented.

The TEM analysis of a polycrystalline Pt film subjected to bulk water OER in $\mathrm{H}_{2} \mathrm{SO}_{4}$ has shown a peculiar characteristic of the electrode with a roughened surface of higher contrast on top of a bulky metallic Pt with cracks exposing new metallic surface [10]. A similarly roughened surface was observed on the TEM of the Pt electrode after our in situ experiments (see Fig. 4c). In both cases, the $\mathrm{O} 1 \mathrm{~s}$ spectra do not show the typical O 1s fingerprint of Pt oxide at $529.6 \mathrm{eV}$, demonstrating the hydroxide character of the present $\mathrm{Pt}^{2+}$ and $\mathrm{Pt}^{4+}$ species. Together with our in situ study, this TEM analysis has enabled us to contribute a hypothesis on the reaction mechanism leading to the formation of the high valence $\mathrm{Pt}$ species earlier considered as OER active species $[57,58]$. In liquid electrolytes upon anodization, the initial oxidation of $\mathrm{Pt}^{0}$ to $\mathrm{Pt}^{\delta+}$ induces the mobilization of $\mathrm{Pt}$ at higher potential according to the equation previously reported [10]:

$\mathrm{Pt}^{\delta+}+4 \mathrm{H}_{2} \mathrm{O}+\mathrm{nH}_{2} \mathrm{O} \rightarrow\left[\mathrm{Pt}\left(\mathrm{H}_{2} \mathrm{O}\right)_{4}\right]^{2+}+\mathrm{nH}_{2} \mathrm{O}+2 \mathrm{e}^{-}$

The Pt aquo complex undergoes condensation according to

$2\left[\mathrm{Pt}\left(\mathrm{H}_{2} \mathrm{O}\right)_{4}\right]^{2+} \rightarrow\left[\mathrm{Pt}_{2}(\mathrm{O})\left(\mathrm{H}_{2} \mathrm{O}\right)_{6}\right]^{2+}+2 \mathrm{H}^{+}+\mathrm{H}_{2} \mathrm{O}$

The dimer in (2) can condense further to hydrous $\mathrm{PtO}$ or oxidize to $\left[\mathrm{Pt}_{2}(\mathrm{O})_{2}\left(\mathrm{H}_{2} \mathrm{O}\right)_{4}\right]^{4+}$ from which hydrous $\mathrm{PtO}_{2}$ and mixed valent oxides are formed. Such a mechanism explains also the formation of single atoms of $\mathrm{Pt}$ on carbon-supported electrodes during OER [59]. Those species might be intermediates in the OER, provided that electronically and coordinatively unsaturated sites are available and the material is electrically conductive. Otherwise, a passivating layer of higher valence states is formed and only the mechanical rupture of it will enable the exposure of further active surface [10]. Due to the low-pressure conditions realized in our experiments, we were able to quench the metastable $\mathrm{Pt}^{\delta+}$ active phase while dissolution/precipitation processes were limited. Consistently, in recent experiments in liquid phase using tender $\mathrm{X}$-ray photoelectron spectroscopy, the $\mathrm{Pt}^{\delta+}$ species was also found on Pt electrodes in alkaline solution and discussed as the relevant species for OER on Pt [8].

Similarly, the reactivity of dry and hydrous Ir oxide-based electrodes has been attributed to the ability of Ir oxides to form instable high oxidation states upon water coordination that free $\mathrm{O}_{2}$ and recover the formal oxidation state [52]. In situ spectroscopic data have failed to confirm the existence of $\operatorname{Ir}(\mathrm{VI})$ states. Only $\operatorname{Ir}(\mathrm{III}), \operatorname{Ir}(\mathrm{IV})$, and $\operatorname{Ir}(\mathrm{V})$ were claimed to be present $[16,53,60]$, but the chemical nature of the oxygen ligands had still not been clarified. This gap was filled by the in situ investigations using the three-electrode cell [12]. The detailed analysis of the O K-edge has provided insights into a likely reaction mechanism: electrophilic oxygen ligands are formed in situ upon polarization $[12,61]$ and will be attacked by nucleophilic $\mathrm{OH}$ species to form $\mathrm{O}_{2}$. The molecular nature of the intermediate species bearing $\mathrm{O}$ ligands able to turn $\mathrm{H}_{2} \mathrm{O}$ in $\mathrm{O}_{2}$ was evident. $\mathrm{We}$ also showed that the OER can occur on only slightly oxidized Ir metal surfaces and that it is not an exclusive ability of the bulk oxide. A recent publication has confirmed that also in liquid environments on an initially metallic Ir, the OER is enhanced upon formation of small, hydrated and 
hydroxylated, non-stoichiometric Ir-O particles at the triplephase and grain boundaries [62].

The need for a careful conduction of experiments monitoring oxygen-evolving electrodes became obvious when investigating the iridium oxides: The evaluation of the onset of the electrophilic $\mathrm{O}^{\mathrm{I}-}$ species forming on Ir was only possible under low dose of X-ray beam due to their beam sensitivity. This limitation manifested itself when considering manganese oxides. Mn in the form of high surface area dendrite-like oxyhydroxide is even more difficult to investigate due to its high beam sensitivity. It will be shown in a follow up contribution that a low dose of X-ray and additional filters are needed to evaluate anodic process over $\mathrm{Mn}$, which are otherwise covered by the reduction induced by ionized water and $\mathrm{e}^{-}$. The poor conductivity of the $\mathrm{Mn}(\mathrm{III} / \mathrm{IV}) \mathrm{OOH}$ seems to lead to its reduction to Mn(II) under the effect of the beam and prevents its anodic oxidation.

We attempt here a hypothesis of a unified reaction concept for the OER on metallic electrodes: Upon polarization, $\mathrm{OH}$ chemisorbs on the electrode surface and the oxidation proceeds with increasing potential. The oxidation of metals is known to be diffusion-limited due to the poor flexibility of the metals to accommodate $\mathrm{O}$ atoms. Thus, as the electrode anodization proceeds, a surface $\mathrm{O}$ oversaturation might occur and a molecular metal species bearing an electrophilic oxygen ligand will form through a one-electron transfer mechanism. This species will then undergo a chemical step in which adjacent $\mathrm{OH}^{-}$attacks the electrophilic $\mathrm{O}^{\mathrm{I}}$, forming an intermediate species that decomposes to $\mathrm{O}_{2}$. If $\mathrm{O}^{\mathrm{II}-}$ is formed instead of $\mathrm{O}^{\mathrm{I}-}$, a higher overpotential for the OER is required. The chemical nature of the nucleophilic attack of $\mathrm{OH}^{-}$, as opposed to the previous electrochemical step, would explain the linear trend observed in Fig. 21c. We thus conclude that the OER is kinetically favoured over the metal oxidation when the metal or metal oxide surface undergoes a transformation path that involves a metastable phase with a higher oxidation state of +1 from the starting value.

When we now explicitly consider the OER in liquid electrolytes, apart from the metal surface and subsurface oxidation, also equilibria of hydrolysis, condensation, and precipitation, which depend on the $\mathrm{pH}$ and solubility constant, should be considered. The dissolution of surface metal ions can expose new phases and generate metastability (which could be beneficial for the $\mathrm{O}_{2}$ turn over). If the material dissolves further, an oversaturation of metal hydroxide species in close proximity to the electrode surface may lead to a condensation reaction and the formation of a precipitate of metal oxyhydroxide [63]. Depending on the nature of the oxyhydroxide layer, it can be detrimental for catalytic activity when it converts into a non-conductive oxide layer as in the case of Pt [54]. In the case of metallic Ir electrodes, however, the Ir oxyhydroxide is conductive and active. $\mathrm{Li}$ et al. [62] have recently observed that it enhances the activity of an initially metallic Ir electrode and is even more reactive but less stable than rutile-type $\mathrm{IrO}_{2}$. The authors go on and show that the process leading to a reduced OER activity on initially metallic iridium electrodes with time is in fact the crystallization of this metastable oxyhydroxide into bulk rutile-type $\mathrm{IrO}_{2}$.

The present work has shown that if $\mathrm{Mn}$ (III)OOH or any other earth-abundant material-based electrode should replace Ir-based catalysts, their design should be driven not only by chemical considerations based on the thermodynamic reduction potential, but also by mechanical/electrical considerations: The macroscopic assembly of the active site needs to be in intimate contact with a conductive support. Moreover, in both the Ir and Pt case, we have indicated that each metal atom undergoes monoelectronic transfers. This type of transfer appears to be a necessary condition for the OER and is probably necessary to form the electrophilic $\mathrm{O}^{\mathrm{I}-}$ species. In contrast, a $2 \mathrm{e}^{-}$electron transfer to a metal atom leads to more strongly bound $\mathrm{O}$ species.

\section{Conclusion}

Herein, we have comprehensively described the technical development of two electrochemical cells to study water splitting materials by near ambient pressure X-ray photoelectron spectroscopy (NAP-XPS). The surface sensitivity of this technique and the broad range of available pressures enable us to investigate and identify the surface elemental composition and chemical state of most of the relevant elements in catalysis at varying conditions.

Our first prototype to study oxygen-evolving electrodes in situ was a batch-like two-electrode cell. Its transient character naturally induced perturbation to the system, which enabled us to identify the relevant redox processes and distinguish them from secondary reaction paths. While the results presented herein have shown the great potential of this cell to study the oxygen evolution reaction (OER), its design entailed several complications preventing investigation under steady state conditions, namely (1) limited water storage ability, (2) lack of reference electrode, (3) overpressure in liquid reservoir due to gas evolution at counter electrode. These limitations motivated the further development of the cell architecture into a three-electrode flow cell, which provided a continuous electrolyte supply and eased the pressure exerted on the membrane from gases evolved at the counter electrode.

Using the two in situ cells at working pressures of $10^{-2}-10^{-1}$ mbar, we were able to observe the initial activation processes of OER-active materials and achieved a high sensitivity towards the dynamics of chemisorbed species. Working in this, compared to atmospheric conditions, low pressure environment quenched the system in its 
initial active state. However, the limited wetting conditions prevented us to evaluate the impact of electrolytes and the equilibria in solution. Regardless, these cells have helped to contribute to the community the working oxidation state of anions and cations of the OER-active surface for Pt, considered as poorly active material for OER, and for IrOx, the state-of-the-art OER catalyst. These investigations have shown that the splitting in formal charges between anions and cations is much less than that anticipated in literature. For the case of Ir, the experiments demonstrated a ligand/ anion-centred oxidation (formation of $\mathrm{O}^{\mathrm{I}-}$ ) during the OER.

While the example of manganese has shown that beamsensitive materials require specifically designed NAP-XPS experiments, the (1) high flexibility, (2) surface-sensitive detection mode with opportunity of depth profiling, and (3) comparative analysis by looking at different chemical entities taking part in the reaction mechanism make NAPXPS incomparable to any other in situ technique. In fact, as seen in the Pt case, the opportunity to extend the pressure range may turn out to be very useful in identifying metastable phases normally not seen with other operando methodologies.

Finally, it appears evident from this report that the pressure range of these PEM-based in situ cells needs to be further enlarged toward higher pressures and to approach realistic operation conditions to further elucidate the role of the electrolyte. New lines of research must consider innovative ideas to entrap the water/electrolyte diffused through the Nafion ${ }^{\circledR}$ membrane and locally enable a liquid phase on the electrode. Further instrumental development should be devoted to controlling the thickness of the water layer.

Acknowledgements The authors gratefully acknowledge Prof. Georg Held for discussion on fitting the Mn spectra, Gisela Weinberg for SEM images, Dr. Travis E. Jones for the calculated $\mathrm{O}^{\mathrm{I}-}$ and $\mathrm{O}^{\mathrm{II}-}$ spectra for the iridium oxides, and Frederic Sulzmann for manganese reference NEXAFS spectra. The authors acknowledge BESSY II/HZB for granting beam time under the proposal \#15202526. This work was further supported by the Ministry of Education and Science of the Russian Federation (RFMEFI61614×0007) and the Bundesministerium für Bildung und Forschung (05K14EWA) through the joint Russian-German research project "SYnchrotron and NEutron STudies for Energy Storage" (SYNESTESia). In addition, the Bundesministerium für Bildung und Forschung funded the project through the MANGAN cluster project Nr. 8.1 NKBF 98.

Open Access This article is distributed under the terms of the Creative Commons Attribution 4.0 International License (http://creativeco mmons.org/licenses/by/4.0/), which permits unrestricted use, distribution, and reproduction in any medium, provided you give appropriate credit to the original author(s) and the source, provide a link to the Creative Commons license, and indicate if changes were made.

\section{References}

1. Leitner W, Quadrelli EA, Schlögl R (2017) Harvesting renewable energy with chemistry. Green Chem 19:2307-2308

2. Schlögl R (2013) Chemical energy storage. DE GRUYTER, Berlin

3. Centi G, Perathoner S (2017) In: Chen W-Y, Suzuki T, Lackner $\mathrm{M}$ (eds) Handbook of climate change mitigation and adaptation. Springer, Cham

4. Salmeron M, Schlögl R (2008) Ambient pressure photoelectron spectroscopy: a new tool for surface science and nanotechnology. Surf Sci Rep 63:169-199

5. Hoster HE, Gasteiger HA (2010) Handbook of fuel cells. Wiley, New York

6. Zhang CJ, Grass ME, McDaniel AH, DeCaluwe SC, El Gabaly F, Liu Z, McCarty KF, Farrow RL, Linne MA, Hussain Z, Jackson GS, Bluhm H, Eichhorn BW (2010) Measuring fundamental properties in operating solid oxide electrochemical cells by using in situ X-ray photoelectron spectroscopy. Nat Mater 9:944-949

7. Axnanda S, Crumlin EJ, Mao B, Rani S, Chang R, Karlsson PG, Edwards MOM, Lundqvist M, Moberg R, Ross P, Hussain Z, Liu Z (2015) Using "tender" X-ray ambient pressure X-Ray photoelectron spectroscopy as a direct probe of solid-liquid interface. Sci Rep 5:9788

8. Favaro M, Valero-Vidal C, Eichhorn J, Toma FM, Ross PN, Yano J, Liu Z, Crumlin EJ (2017) Elucidating the alkaline oxygen evolution reaction mechanism on platinum. J Mater Chem A 5:11634-11643

9. Han Y, Axnanda S, Crumlin EJ, Chang R, Mao B, Hussain Z, Ross PN, Li Y, Liu Z (2018) Observing the electrochemical oxidation of Co metal at the solid/liquid interface using ambient pressure X-ray photoelectron spectroscopy. J Phys Chem B 122:666-671

10. Arrigo R, Hävecker M, Schuster ME, Ranjan C, Stotz E, KnopGericke A, Schlögl R (2013) In situ study of the gas-phase electrolysis of water on platinum by NAP-XPS. Angew Chem Int Ed 52:11660-11664

11. Law YT, Zafeiratos S, Neophytides SG, Orfanidi A, Costa D, Dintzer T, Arrigo R, Knop-Gericke A, Schlögl R, Savinova ER (2015) In situ investigation of dissociation and migration phenomena at the Pt/electrolyte interface of an electrochemical cell. Chem Sci 6:5635-5642

12. Pfeifer V, Jones TE, Velasco Velez JJ, Arrigo R, Piccinin S, Hävecker M, Knop-Gericke A, Schlögl R (2017) In situ observation of reactive oxygen species forming on oxygen-evolving iridium surfaces. Chem Sci 8:2143-2149

13. Velasco-Velez JJ, Pfeifer V, Hävecker M, Weatherup RS, Arrigo R, Chuang C-H, Stotz E, Weinberg G, Salmeron M, Schlögl R, Knop-Gericke A (2015) Photoelectron spectroscopy at the graphene-liquid interface reveals the electronic structure of an electrodeposited cobalt/graphene electrocatalyst. Angew Chem Int Ed 54:14554-14558

14. Knop-Gericke A, Pfeifer V, Velasco-Velez JJ, Jones T, Arrigo R, Hävecker M, Schlögl R (2017) In situ X-ray photoelectron spectroscopy of electrochemically active solid-gas and solid-liquid interfaces. J Electron Spectrosc Relat Phenom 221:10-17

15. Mierwaldt D, Mildner S, Arrigo R, Knop-Gericke A, Franke E, Blumenstein A, Hoffmann J, Jooss C (2014) In situ XANES/XPS investigation of doped manganese perovskite catalysts. Catalysts 4:129

16. Sanchez Casalongue HG, Ng ML, Kaya S, Friebel D, Ogasawara $\mathrm{H}$, Nilsson A (2014) In situ observation of surface species on iridium oxide nanoparticles during the oxygen evolution reaction. Angew Chem Int Ed 126:7297-7300

17. Sanchez Casalongue HG, Kaya S, Viswanathan V, Miller DJ, Friebel D, Hansen HA, Norskov JK, Nilsson A, Ogasawara H (2013) 
Direct observation of the oxygenated species during oxygen reduction on a platinum fuel cell cathode. Nat Commun 4:2817

18. Cavalca F, Ferragut R, Aghion S, Eilert A, Diaz-Morales O, Liu C, Koh AL, Hansen TW, Pettersson LGM, Nilsson A (2017) Nature and distribution of stable subsurface oxygen in copper electrodes during electrochemical $\mathrm{CO}_{2}$ reduction. J Phys Chem C 121:25003-25009

19. Papaefthimiou V, Shishkin M, Niakolas DK, Athanasiou M, Law YT, Arrigo R, Teschner D, Hävecker M, Knop-Gericke A, Schlögl R, Ziegler T, Neophytides SG, Zafeiratos S (2013) Solid oxide fuel cells: on the active surface state of nickel-ceria solid oxide fuel cell anodes during methane electrooxidation. Adv Energy Mater 3:690-690

20. Toghan A, Arrigo R, Knop-Gericke A, Imbihl R (2012) Ambient pressure X-ray photoelectron spectroscopy during electrochemical promotion of ethylene oxidation over a bimetallic Pt-Ag/YSZ catalyst. J Catal 296:99-109

21. Kolmakov A, Dikin DA, Cote LJ, Huang JX, Abyaneh MK, Amati M, Gregoratti L, Gunther S, Kiskinova M (2011) Graphene oxide windows for in situ environmental cell photoelectron spectroscopy. Nat Nanotechnol 6:651-657

22. Masuda T, Yoshikawa H, Noguchi H, Kawasaki T, Kobata M, Kobayashi K, Uosaki K (2013) In situ X-ray photoelectron spectroscopy for electrochemical reactions in ordinary solvents. Appl Phys Lett 103:111605

23. Takagi Y, Wang H, Uemura Y, Nakamura T, Yu L, Sekizawa O, Uruga T, Tada M, Samjeske G, Iwasawa Y, Yokoyama T (2017) In situ study of oxidation states of platinum nanoparticles on a polymer electrolyte fuel cell electrode by near ambient pressure hard X-ray photoelectron spectroscopy. Phys Chem Chem Phys 19:6013-6021

24. Brown MA, Bossa GV, May S (2015) Emergence of a stern layer from the incorporation of hydration interactions into the Gouy-Chapman model of the electrical double layer. Langmuir 31:11477-11483

25. Carmo M, Fritz DL, Mergel J, Stolten D (2013) A comprehensive review on PEM water electrolysis. Int J Hydrogen Energy 38:4901-4934

26. Grot WG (1994) Perfluorinated ion exchange polymers and their use in research and industry. Macromol Symp 82:161-172

27. Heitner-Wirguin C (1996) Recent advances in perfluorinated ionomer membranes: structure, properties and applications. J Memb Sci 120:1-33

28. Söhn M (2010) Kohenstoff-Nanoröhrchen als Elektrodenmaterial für PEM-Brennstoffzellen. Dissertation, TU Darmstadt, Darmstadt

29. Knop-Gericke A, Kleimenov E, Hävecker M, Blume R, Teschner D, Zafeiratos S, Schlögl R, Bukhtiyarov VI, Kaichev VV, Prosvirin IP, Nizovskii AI, Bluhm H, Barinov A, Dudin P, Kiskinova M (2009) In: Bruce CG, Helmut K (eds) Advances in catalysis. Academic Press, Waltham

30. Hävecker M, Cavalleri M, Herbert R, Follath R, Knop-Gericke A, Hess C, Hermann K, Schlögl R (2009) Methodology for the structural characterisation of $\mathrm{VxOy}$ species supported on silica under reaction conditions by means of in situ O K-edge X-ray absorption spectroscopy. Phys Status Solidi B 246:1459-1469

31. DeGroot F, Kotani A (2008) Core level spectroscopy of solids. CRC Press, Boca Raton

32. Zhu Z, Tao F, Zheng F, Chang R, Li Y, Heinke L, Liu Z, Salmeron M, Somorjai GA (2012) Formation of nanometer-sized surface platinum oxide clusters on a stepped Pt(557) single crystal surface induced by oxygen: a high-pressure STM and ambient-pressure XPS study. Nano Lett 12:1491-1497

33. Favaro M, Jeong B, Ross PN, Yano J, Hussain Z, Liu Z, Crumlin EJ (2016) Unravelling the electrochemical double layer by direct probing of the solid/liquid interface. Nat Commun 7:12695
34. Nagasaka M, Nakai I, Kondoh H, Ohta T, Carravetta V (2003) Oxygen K-edge near edge X-ray absorption fine structures of $\mathrm{O}$ and $\mathrm{OH}$ overlayers on $\mathrm{Pt}(111)$. Chem Phys Lett 375:419-424

35. Bluhm H, Ogletree DF, Fadley CS, Hussain Z, Salmeron M (2002) The premelting of ice studied with photoelectron spectroscopy. J Phys Cond Matter 14:L227

36. Le Vot S, Roué L, Bélanger D (2012) Electrodeposition of iridium onto glassy carbon and platinum electrodes. Electrochim Acta 59:49-56

37. Pfeifer V, Jones TE, Velasco Vélez JJ, Massué C, Greiner MT, Arrigo R, Teschner D, Girgsdies F, Scherzer M, Allan J, Hashagen M, Weinberg G, Piccinin S, Hävecker M, Knop-Gericke A, Schlögl R (2016) The electronic structure of iridium oxide electrodes active in water splitting. Phys Chem Chem Phys 18:2292-2296

38. Pfeifer V, Jones TE, Velasco Vélez JJ, Massué C, Arrigo R, Teschner D, Girgsdies F, Scherzer M, Greiner MT, Allan J, Hashagen M, Weinberg G, Piccinin S, Hävecker M, Knop-Gericke A, Schlögl R (2016) The electronic structure of iridium and its oxides. Surf Interface Anal 48:261-273

39. Armstrong FA (2008) Why did Nature choose manganese to make oxygen? Philos Trans R Soc Lond B 363:1263-1270

40. Zhao D, Yang Z, Zhang L, Feng X, Zhang Y (2011) Electrodeposited manganese oxide on nickel foam-supported carbon nanotubes for electrode of supercapacitors. Electrochem Solid-State Lett 14:A93-A96

41. Sulzmann F, Jones TE, Knop-Gericke A, Schlögl R, Skorupska K (2019) in preparation

42. van Schooneveld MM, DeBeer S (2015) A close look at dose: toward L-edge XAS spectral uniformity, dose quantification and prediction of metal ion photoreduction. J Electron Spectrosc Relat Phenom 198:31-56

43. Mette K, Bergmann A, Tessonnier J-P, Hävecker M, Yao L, Ressler T, Schlögl R, Strasser P, Behrens M (2012) Nanostructured manganese oxide supported on carbon nanotubes for electrocatalytic water splitting. ChemCatChem 4:851-862

44. Khan M, Xiao J, Zhou F, Yablonskikh M, MacFarlane DR, Spiccia L, Aziz EF (2015) On the origin of the improvement of electrodeposited $\mathrm{MnOx}$ films in water oxidation catalysis induced by heat treatment. ChemSusChem 8:1980-1985

45. Fuller FD, Gul S, Chatterjee R, Burgie ES, Young ID, Lebrette H, Srinivas V, Brewster AS, Michels-Clark T, Clinger JA, Andi B, Ibrahim M, Pastor E, de Lichtenberg C, Hussein R, Pollock CJ, Zhang M, Stan CA, Kroll T, Fransson T, Weninger C, Kubin M, Aller P, Lassalle L, Bräuer P, Miller MD, Amin M, Koroidov S, Roessler CG, Allaire M, Sierra RG, Docker PT, Glownia JM, Nelson S, Koglin JE, Zhu D, Chollet M, Song S, Lemke H, Liang M, Sokaras D, Alonso-Mori R, Zouni A, Messinger J, Bergmann U, Boal AK, Bollinger JM Jr, Krebs C, Högbom M, Phillips GN Jr, Vierstra RD, Sauter NK, Orville AM, Kern J, Yachandra VK, Yano J (2017) Drop-on-demand sample delivery for studying biocatalysts in action at X-ray free-electron lasers. Nat Methods $14: 443$

46. Risch M, Stoerzinger KA, Han B, Regier TZ, Peak D, Sayed SY, Wei C, Xu Z, Shao-Horn Y (2017) Redox processes of manganese oxide in catalyzing oxygen evolution and reduction: an in situ soft X-ray absorption spectroscopy study. J Phys Chem C 121:17682-17692

47. Capon A, Parsons R (1972) Effect of strong acid on reactions of hydrogen and oxygen on noble-metals: study using cyclic voltammetry and a new teflon electrode holder. J Electroanal Chem 39:275-286

48. Burke LD, Scannell RA (1988) The effect of UV-light on the hydrous oxides of iridium. J Electroanal Chem 257:101-121 
49. Outka DA, Stöhr J, Madix RJ, Rotermund HH, Hermsmeier B, Solomon J (1987) NEXAFS studies of complex alcohols and carboxylic acids on the $\operatorname{Si}(111)(7 \times 7)$ surface. Surf Sci 185:53-74

50. Rodriguez JA, Jirsak T, Freitag A, Hanson JC, Larese JZ, Chaturvedi $\mathrm{S}$ (1999) Interaction of $\mathrm{SO}_{2}$ with $\mathrm{CeO}_{2}$ and $\mathrm{Cu} / \mathrm{CeO}_{2}$ catalysts: photoemission, XANES and TPD studies. Catal Lett 62:113-119

51. Chaturvedi S, Rodriguez JA, Brito JL (1998) Characterization of pure and sulfided $\mathrm{NiMoO}_{4}$ catalysts using synchrotron-based $\mathrm{X}$-ray absorption spectroscopy (XAS) and temperature-programmed reduction (TPR). Catal Lett 51:85-93

52. Kötz R, Neff H, Stucki S (1984) Anodic iridium oxide films: XPSstudies of oxidation state changes and $\mathrm{O}_{2}$-evolution. J Electrochem Soc 131:72-77

53. Minguzzi A, Lugaresi O, Achilli E, Locatelli C, Vertova A, Ghigna P, Rondinini S (2104) Observing the oxidation state turnover in heterogeneous iridium-based water oxidation catalysts. Chem Sci 5:3591-3597

54. Pfeifer V, Jones TE, Wrabetz S, Massué C, Velasco Vélez JJ, Arrigo R, Scherzer M, Piccinin S, Hävecker M, Knop-Gericke A, Schlögl R (2016) Reactive oxygen species in iridium-based OER catalysts. Chem Sci 7:6791-6795

55. Trasatti S (1984) Electrocatalysis in the anodic evolution of oxygen and chlorine. Electrochim Acta 29:1503-1512

56. Johnson B, Ranjan C, Greiner MT, Arrigo R, Schuster ME, Höpfner B, Gorgoi M, Lauermann I, Willinger MG, Knop-Gericke A, Schlögl R (2016) ChemSusChem 9:1634
57. Reddy AKN, Genshaw M, Bockris JO (1964) Ellipsometric study of oxygen-containing films on platinum electrodes. J Electroanal Chem 8:406

58. Churchill CR, Hibbert DB (1982) Kinetics of the electrochemical evolution of isotopically enriched gases. Part 1: 180160 evolution on platinum in acid and alkaline solution. J Chem Soc Faraday Trans 178:2937-2945

59. Schlögl R, Kudrenko E, Willinger MG, Yi Y, Arrigo R, Schüth F (2013) Pt nanoparticles as electrocatalysts for water splitting: atomistic insights into functions and stability. Microsc Microanal 19:1444-1445

60. Cherevko S, Geiger S, Kasian O, Mingers A, Mayrhofer KJJ (2016) Oxygen evolution activity and stability of iridium in acidic media. Part 2: electrochemically grown hydrous iridium oxide. J Electroanal Chem 774:102-110

61. Saveleva VA, Wang L, Teschner D, Jones TE, Gago AS, Friedrich KA, Zafeiratos S, Schlögl R, Savinova ER (2018) Operando evidence for a universal oxygen evolution mechanism on thermal and electrochemical iridium oxides. J Phys Chem Lett 9:3154-3160

62. Li T, Kasian O, Cherevko S, Zhang S, Geiger S, Scheu C, Felfer P, Raabe D, Gault B, Mayrhofer KJJ (2018) Atomic-scale insights into surface species of electrocatalysts in three dimensions. Nat Catal 1:300-305

63. Binninger T, Mohamed R, Waltar K, Fabbri E, Levecque P, Kötz R, Schmidt TJ (2015) Thermodynamic explanations of the universal correlation between oxygen evolution activity and corrosion of oxide catalysts. Sci Rep 5:12167 